Results of the Sixth International Comparison of Absolute Gravimeters, ICAG-2001

This article has been downloaded from IOPscience. Please scroll down to see the full text article. 2002 Metrologia 39407

(http://iopscience.iop.org/0026-1394/39/5/2)

The Table of Contents and more related content is available

Download details:

IP Address: 128.83.54.92

The article was downloaded on 12/04/2010 at 20:00

Please note that terms and conditions apply. 


\title{
Results of the Sixth International Comparison of Absolute Gravimeters, ICAG-2001
}

L. Vitushkin, M. Becker, Z. Jiang, O. Francis, T. M. van Dam, J. Faller, J.-M. Chartier, M. Amalvict, S. Bonvalot, N. Debeglia, S. Desogus, M. Diament, F. Dupont, R. Falk, G. Gabalda, C. G. L. Gagnon, T. Gattacceca, A. Germak, J. Hinderer, O. Jamet, G. Jeffries, R. Käker, A. Kopaev, J. Liard, A. Lindau, L. Longuevergne, B. Luck, E. N. Maderal, J. Mäkinen, B. Meurers, S. Mizushima, J. Mrlina, D. Newell, C. Origlia, E. R. Pujol, A. Reinhold, Ph. Richard, I. A. Robinson, D. Ruess, S. Thies, M. Van Camp, M. Van Ruymbeke, M. F. de Villalta Compagni and S. Williams

\begin{abstract}
The Sixth International Comparison of Absolute Gravimeters was held from 5 June to 28 August 2001 at the Bureau International des Poids et Mesures (BIPM), Sèvres. Seventeen absolute gravimeters were used to make measurements at five sites of the BIPM gravity network. The vertical gravity gradients at the sites and the ties between them were also measured using seventeen relative gravimeters. For the first time the ties were also measured using absolute gravimeters. Various methods of processing the absolute and relative data were tested to calculate the results. The final results of ICAG-2001 are presented. The acceleration due to gravity at a height of $0.90 \mathrm{~m}$ is given as $(980925701.2 \pm 5.5) \mu \mathrm{Gal}^{*}$ and $(980928018.8 \pm 5.5) \mu \mathrm{Gal}$ for sites $\mathrm{A}$ and $\mathrm{B}$, respectively, calculated using a combined adjustment of the absolute and relative data.
\end{abstract}

J.-M. Chartier, Z. Jiang and L. Vitushkin: Bureau International des Poids et Mesures (BIPM), Sèvres, France.

M. Becker: Institut für Geodäsie (IfG), Universität der Bundeswehr, Neubiberg, Germany.

O. Francis and T. M. van Dam: European Center for Geodynamics and Seismology (ECGS), Luxembourg.

J. Faller: JILA, University of Colorado-National Institute of Standards and Technology (NIST), Boulder, CO, USA.

M. Amalvict, B. Luck and J. Hinderer: École et Observatoire des Sciences de la Terre (EOST), Strasbourg, France.

S. Bonvalot, G. Gabalda and L. Longuevergne: Institut de Recherche pour le Développement (IRD), Bondy, France.

N. Debeglia and F. Dupont: Bureau de Recherches Géologiques et Minières (BRGM), Orléans, France.

S. Desogus, A. Germak and C. Origlia: Istituto di Metrologia "G. Colonnetti” (IMGC), Turin, Italy.

M. Diament: Institut de Physique du Globe de Paris (IPGP), Paris, France.

R. Falk and A. Reinhold: Bundesamt für Kartographie und Geodäsie (BKG), Frankfurt, Germany.

C. G. L. Gagnon and J. Liard: Natural Resources Canada (NRCan), Ottawa, Canada.

T. Gattacceca: Institut Géographique National (IGN), Saint-Mandé, France.

O. Jamet, École Nationale des Sciences Géographiques (ENSG), Marne-la-Vallée, France.
G. Jeffries and S. Williams: Proudman Oceanographic Laboratory (POL), Bidston, UK.

R. Käker and A. Lindau: Institut für Erdmessung (IfE), Universität Hannover, Hanover, Germany.

A. Kopaev: Sternberg Astronomical Institute (SAI), Moscow State University, Moscow, Russian Federation.

E. N. Maderal, E. R. Pujol and M. F. de Villalta Compagni: Instituto Geográfico Nacional (IGN), Madrid, Spain.

J. Mäkinen: Finnish Geodetic Institute (FGI), Masala, Finland.

B. Meurers: Institute für Meteorologie und Geophysik (IMG), Universität Wien, Vienna, Austria.

S. Mizushima: National Metrology Institute of Japan, National Institute of Advanced Industrial Science and Technology (NMIJ/AIST), Tsukuba, Japan.

J. Mrlina: Geophysical Institute (GFÚ) AS CR, Prague, Czech Republic.

D. Newell: National Institute of Standards and Technology (NIST), Gaithersburg, USA.

Ph. Richard and S. Thies: Swiss Federal Office of Metrology and Accreditation (METAS), Bern-Wabern, Switzerland.

I. A. Robinson: National Physical Laboratory (NPL), Teddington, UK.

D. Ruess: Bundesamt für Eich- und Vermessungswesen (BEV), Vienna, Austria.

M. Van Camp and M. Van Ruymbeke: Observatoire Royal de Belgique (ORB), Brussels, Belgium.

$* 1 \mathrm{Gal}=1 \mathrm{~cm} \mathrm{~s}^{-2}$. 


\section{Introduction}

The Sixth International Comparison of Absolute Gravimeters, ICAG-2001, continues the series of such comparisons started in 1981 [1-10]. All the ICAGs have been organized jointly by the BIPM and Working Group 6 (Comparison of Absolute Gravimeters) of the International Gravity Commission (IGC) and from 1999 by the International Gravity and Geoid Commission (IGGC). Like the previous comparisons, ICAG-2001 was held at the BIPM (Sèvres, France). Seventeen absolute gravimeters (AGs), from twelve countries and the BIPM, and seventeen relative gravimeters (RGs) from eight countries were used during the comparison, which ran from June to August 2001 and (for the IMGC group) from 27 September to 2 October 2001.

To allow all the measurements to be made within this relatively short period, the BIPM has constructed an additional site for $g$ measurements in its new building, the Pavillon du Mail. Seven sites of the BIPM gravity network were used for the relative measurements and five for the absolute measurements.

On the basis of experience gained in the previous comparisons, and considering the increasing number of absolute gravimeters worldwide and their emerging role as primary standards in gravimetry, a joint meeting of the ICAG-2001 steering committee and IGGC Working Groups 6 and 8 defined the following goals for the comparison. The primary objective of ICAG2001 was to determine the level of uncertainty in the absolute measurement of free-fall acceleration $g$ on the ground and to evaluate the possibility of determining a comparison reference value [11] for $g$ at the sites of the BIPM gravity micro-network. Such a reference value, as usually determined in a key comparison [11], would allow correction values to be determined for the results of the gravimeters participating in the comparison.

Regarding this primary objective, the specific goals of ICAG-2001 were

- to establish an updated gravity micro-network at the BIPM;

- to use both AGs and RGs to measure the ties of the gravity micro-network;

- to establish a data-evaluation procedure for absolute and relative measurements during this and future ICAGs;

- to determine the absolute $g$ values and vertical gravity gradients at the BIPM sites;

- to determine the uncertainties in absolute and relative measurements.

Various combinations of absolute and relative data (absolute only, or combined absolute and relative) were adjusted to determine the absolute $g$ values at the BIPM sites and the results were compared with those obtained when adjusting only the relative data. The combined adjustment, achieved in an ICAG for the first time, yielded both $g$ values at the sites, which are important for long-term analysis of variations of the gravity field at the BIPM gravity network, and an estimate of the uncertainty of the measurements. In previous ICAGs the gravity ties measured only by relative gravimeters were used to transfer the $g$ values from site to site, and the final result of comparisons, i.e. the mean value of all the results of the absolute measurements transferred to the reference point, was calculated using these ties. The combined adjustment used in the calculation of the results of ICAG-2001 provides the $g$ values at all the sites and, subsequently, the ties between the sites.

The number of absolute gravimeters is increasing, and network ties can now be measured using an AG alone. This changes the role of absolute gravimeters [12], which are becoming the primary standards in gravimetry in place of the traditional gravity networks. It is important to investigate the achievable level of uncertainty and to compare measurements of the network using relative and absolute gravimeters. The potential accuracy of ballistic absolute gravimeters has been estimated in various publications (see, for example, [13]) but only the ICAGs provide an opportunity to compare practical measurements of the ties using numerous relative and absolute gravimeters.

Two different kinds of observation equation were used for the adjustment of the relative data. The first was based on the readings of the relative gravimeters $[8,10]$, and the second used the differences between these readings [14].

The use of various approaches to data processing improves understanding of the analysis of the absolute and relative results and provides a basis for the choice of data-processing method to be used in future gravimeter comparisons. Such details might be included in the technical protocol of a future comparison, to bring under regulation its organization, measurement strategy, method of data processing and presentation of the results of the comparison.

\section{BIPM gravity network}

The construction at the BIPM of a new building, the Pavillon du Mail, made it possible to extend the gravity network by creating a number of new sites for $g$ measurements. The foundation for the new sites (B, $\mathrm{B} 1, \mathrm{~B} 2, \mathrm{~B} 3$ and B4) is a concrete block with a mass of more than 70 tonnes and dimensions $6.0 \mathrm{~m}$ (length) $\times 4.0 \mathrm{~m}$ (width) $\times 1.5 \mathrm{~m}$ (depth). The top surface of the foundation is levelled to the floor to minimize inhomogeneity of the gravity field. This construction differs from that of the pillars of sites A and A2, which have a height of about $2.4 \mathrm{~m}$ above floor level in the basement. To improve isolation from micro-seismic vibrations, the new foundation is installed on pads of an elastic material inserted between its lower surface and the bottom of the hole in the concrete basement. No metal reinforcing bars were used in the construction 


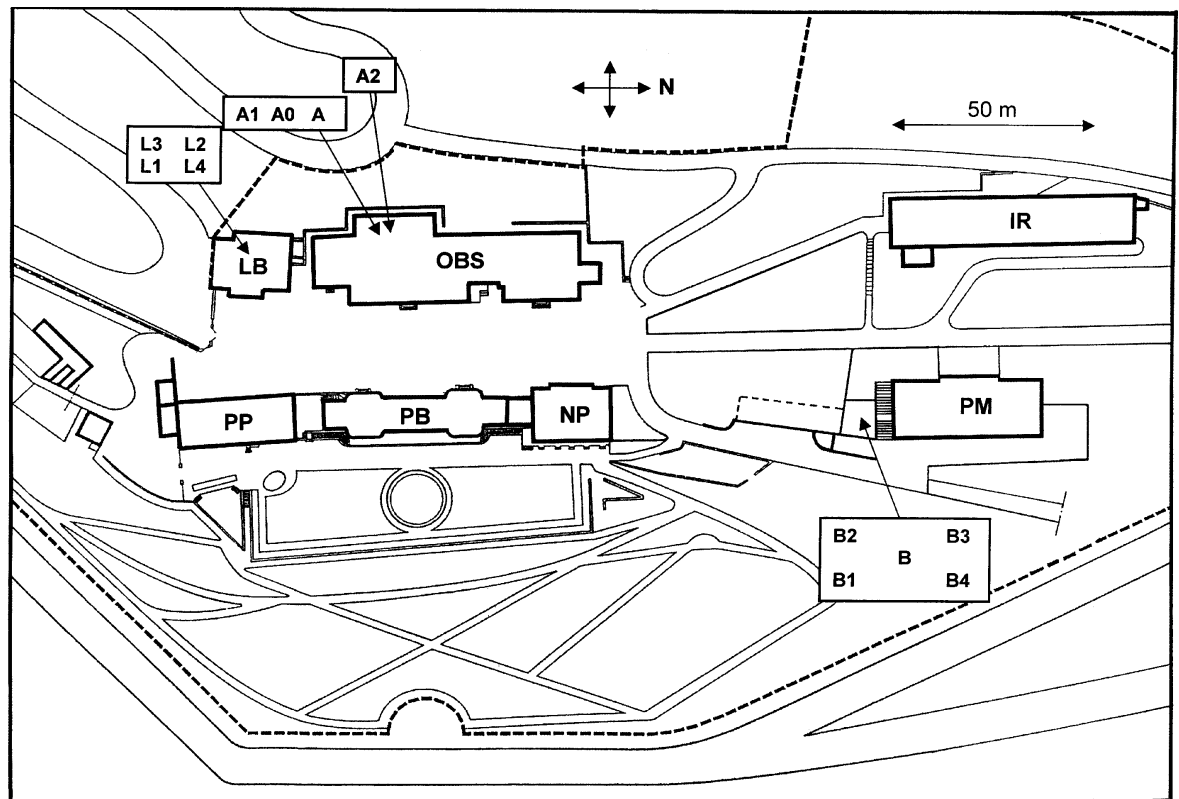

Figure 1a. Location of the sites of the BIPM gravity micro-network. LB: laser building; OBS: observatory building, IR: ionizing radiation building; PP: Petit Pavillon; PB: Pavillon de Breteuil; NP: Nouveau Pavillon; PM: Pavillon du Mail.

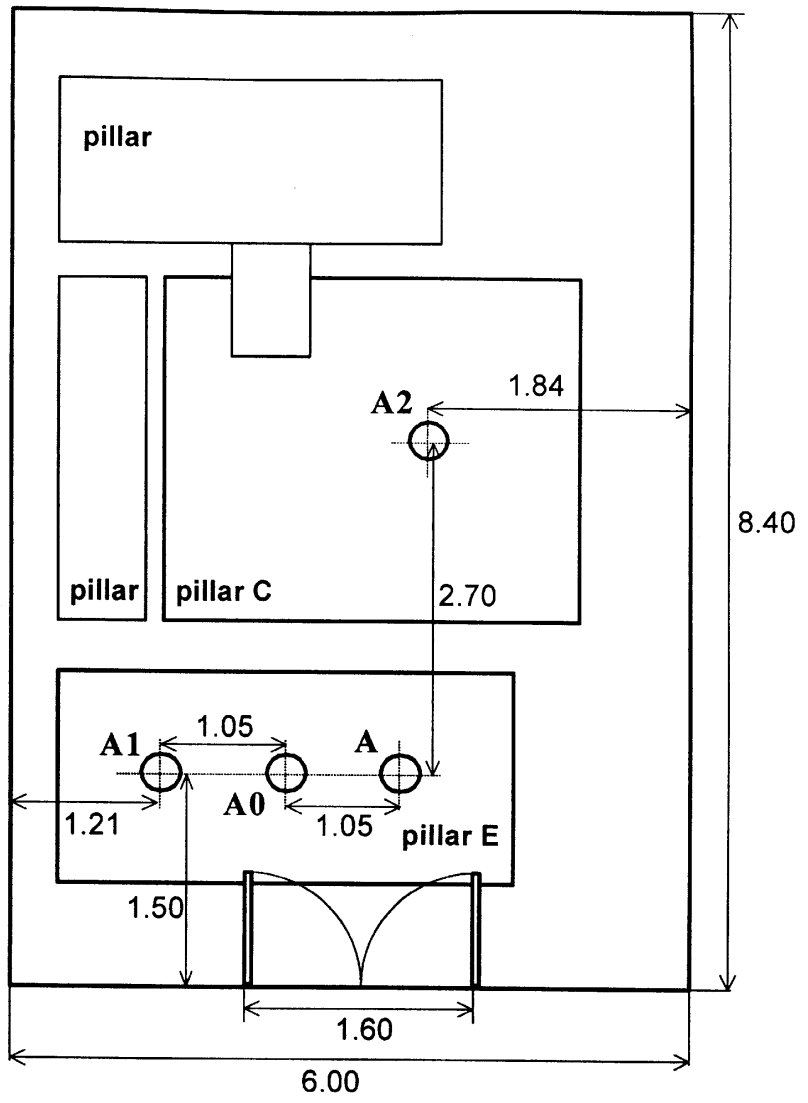

Figure 1b. Sites A, A0, A1 and A2 (dimensions in metres).

of this foundation. Figure 1a shows the distribution of the sites. Details $1 \mathrm{~b}, 1 \mathrm{c}$ and $1 \mathrm{~d}$ show the locations of the measurement points at each site. The foundation in the laser building (Figure 1a) is a concrete block approximately $30 \mathrm{~cm}$ thick, lying on a sand-bed.

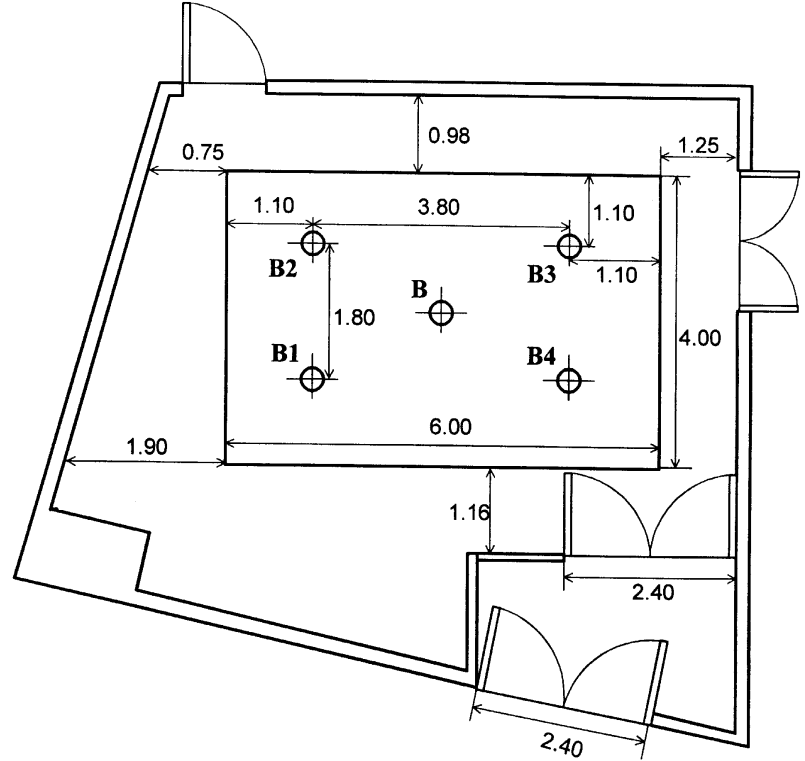

Figure 1c. Sites B, B1 to B4 (dimensions in metres).

Sites A, A2, L3, L4, B, B1 and B3 were used for the relative $g$ measurements and sites A, A2, B, B1 and B3 for the absolute measurements. The $g$ values at these sites vary by up to $2.3 \mathrm{mGal}$ at floor level (Table 2). Compared with previous ICAGs this improves capacity to check and monitor the calibration parameters of the relative gravimeters and their feedback systems.

During the comparisons in 1994 and 1997 it was found that the sites of the BIPM outdoor calibration line suffer poor environmental conditions (high level of micro-seismic noise, etc.), so this calibration line was not used for ICAG-2001. 


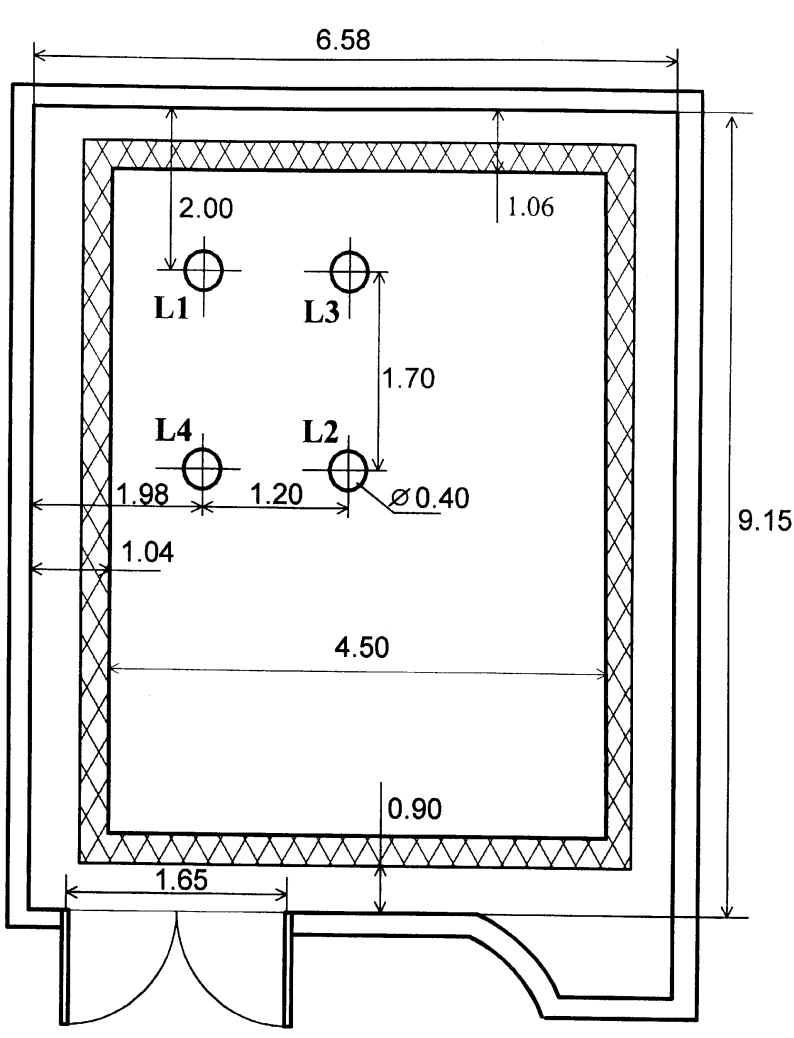

Figure 1d. Sites L1 to L4 (dimensions in metres).

Site B3 was used for almost continuous monitoring of the gravity field during the principal period of absolute $g$ measurements, from 30 June to 3 August 2001, using the BIPM absolute gravimeter FG5-108.

Levelling (measurement of the altitudes) of the sites A, A2, B, B1, B2, B3, B4, L3 and L4 was carried out in June 2001 by Debeglia and Dupont of the Bureau de Recherches Géologiques et Minières (BRGM), France.

\section{Participants in ICAG-2001}

Table 1 lists participants in ICAG-2001 together with their gravimeters. The absolute gravimeters may be classified into four main groups: JILA-type gravimeters, FG5-type gravimeters, the A10 gravimeter and the IMGC gravimeter. The FG5 group may be split into at least three subdivisions differing in composition (dropper mechanism, length of free-fall path of the test body, laser interferometer unit, the use of a fibre-coupled or incorporated laser, modifications of the electronic units, software, etc.). Only the IMGC gravimeter is of a rise-fall type. The relative gravimeters were of three main types: LaCoste-Romberg (LCR), Scintrex and Sodin.

\section{Relative gravimetry series of measurements and data processing}

In this section only a brief review is presented of the organization, measurements, data-processing principles and most important numerical results of the relative $g$ measurements of ICAG-2001. A detailed analysis of the relative measurements will be published in a dedicated paper. General discussions, related to the previous comparisons, on the relative $g$ measurements required for the determination of $g$-value differences between pillars (network ties) and vertical gravity gradients above the pillars, can be found in $[1-4,6,8,10]$.

\subsection{Relative $g$ measurements}

Measurements of the network ties and gradients at each site were made separately. The height of the gravity field sensor of the relative gravimeter was brought close to the reference heights (listed below). For the network determination each gravimeter measured three loops, defined as a continuous sequence of measurements. The loops were established such that each yielded at least one direct tie between any pair of sites of the network. The various points were measured at quasiequal time intervals so that the measurement accuracy was homogeneous and correction of the zero-drift of the gravimeters was facilitated. Five loops with fixed tie configurations were proposed. Figure 2 shows loop 1 (sites L4, B1, B, L4, A, B, A2, A, L3, A2, L4, L3, $\mathrm{B} 1, \mathrm{~A}, \mathrm{~A} 2, \mathrm{~B} 1, \mathrm{~B}, \mathrm{~L} 3)$.

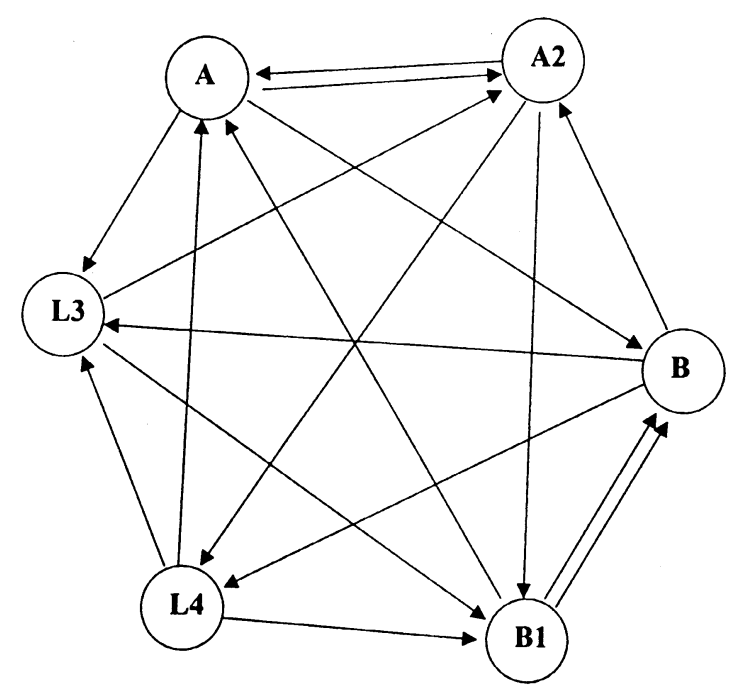

Figure 2. The loop for relative measurements during ICAG-2001.

In order to reduce the gradient correction error in the absolute measurements, the network was defined and measured at a height of $0.9 \mathrm{~m}$ above a benchmark defined by a cross engraved on the cover plug over the aluminium disk installed at each site. The total thickness of the disk including its plug is $12 \mathrm{~mm}$. The height $0.9 \mathrm{~m}$ is an intermediate reference height for absolute $g$ measurements, consistent with that chosen for previous comparisons and corresponding approximately to the average height of attribution of $g$ for the absolute gravimeters. 
Table 1. Participants in ICAG-2001 and their gravimeters.

\begin{tabular}{|c|c|c|c|c|}
\hline Country & Institution & $\begin{array}{l}\text { Absolute } \\
\text { gravimeter(s) }\end{array}$ & $\begin{array}{l}\text { Relative } \\
\text { gravimeter(s) }\end{array}$ & $\begin{array}{l}\text { Participation } \\
\text { in ICAG-97 }\end{array}$ \\
\hline Austria & Bundesamt für Eich- und Vermessungswesen (BEV), Vienna & JILAg-6 & LCR-D51 & JILAg-6 \\
\hline Austria & Institute für Meteorologie und Geophysik (IMG), Universität Wien, Vienna & - & LCR-G625 & $\begin{array}{l}\text { LCR-D009 } \\
\text { LCR-G625 }\end{array}$ \\
\hline Belgium & Observatoire Royal de Belgique (ORB), Brussels & FG5-202 & $\begin{array}{l}\text { LCR-G206, } \\
\text { Scintrex-256 }\end{array}$ & $\begin{array}{l}\text { FG5-202, } \\
\text { LCR-G487 }\end{array}$ \\
\hline Canada & Natural Resources Canada (NRCan), Ottawa & $\begin{array}{l}\text { JILA-2, } \\
\text { A10-003 }\end{array}$ & - & $\begin{array}{l}\text { JILA-2, } \\
\text { LCR-D006 } \\
\text { LCR-D028 }\end{array}$ \\
\hline $\begin{array}{l}\text { Czech } \\
\text { Republic }\end{array}$ & Geophysical Institute (GFÚ) AS CR, Prague & - & LCR-D188 & - \\
\hline Finland & Finnish Geodetic Institute (FGI), Masala & JILAg-5 & & JILAg-5 \\
\hline France & Bureau de Recherches Géologiques et Minières (BRGM), Orléans & - & Scintrex-245 & - \\
\hline France & $\begin{array}{l}\text { Institut de Recherche pour le Développement (IRD), Bondy; } \\
\text { Institut de Physique du Globe de Paris (IPGP), Paris; } \\
\text { École Nationale des Sciences Géographiques (ENSG), Marne-la-Vallée }\end{array}$ & & $\begin{array}{l}\text { Scintrex-136, } \\
\text { Scintrex-193, } \\
\text { Scintrex-323 }\end{array}$ & $\begin{array}{l}\text { Scintrex-136, } \\
\text { Scintrex-193 }\end{array}$ \\
\hline France & Institut Géographique National (IGN), Saint-Mandé & - & $\begin{array}{l}\text { Scintrex-408, } \\
\text { Scintrex-379 }\end{array}$ & - \\
\hline France & École et Observatoire des Sciences de la Terre (EOST), Strasbourg & FG5-206 & - & FG5-206 \\
\hline Germany & Bundesamt für Kartographie und Geodäsie (BKG), Frankfurt & $\begin{array}{l}\text { FG5-101, } \\
\text { FG5-301, } \\
\text { A10-b002 }\end{array}$ & - & $\begin{array}{l}\text { FG5-101, } \\
\text { LCR-D0211 }\end{array}$ \\
\hline Germany & Institut für Erdmessung (IfE), Universität Hannover, Hanover & & $\begin{array}{l}\text { LCR-G079, } \\
\text { LCR-G368, } \\
\text { LCR-G709 }\end{array}$ & $\begin{array}{l}\text { LCR-G298, } \\
\text { LCR-G709 }\end{array}$ \\
\hline Italy & Istituto di Metrologia "G. Colonnetti" (IMGC), Turin & IMGC & - & IMGC \\
\hline Japan & $\begin{array}{l}\text { National Metrology Institute of Japan, National Institute of Advanced Industrial } \\
\text { Science and Technology (NMIJ/AIST), Tsukuba }\end{array}$ & FG5-213 & - & - \\
\hline $\begin{array}{l}\text { Russian } \\
\text { Federation }\end{array}$ & $\begin{array}{l}\text { Sternberg Astronomical Institute of Moscow State University (SAI MSU), } \\
\text { Moscow }\end{array}$ & - & Sodin-212 & - \\
\hline Spain & Instituto Geográfico Nacional (IGN), Madrid & FG5-211 & - & - \\
\hline Switzerland & Swiss Federal Office of Metrology and Accreditation (METAS), Bern-Wabern & FG5-209 & Scintrex-494 & - \\
\hline UK & National Physical Laboratory (NPL), Teddington & FG5-105 & - & FG5-105 \\
\hline UK & Proudman Oceanographic Laboratory (POL), Bidston & FG5-103 & - & FG5-103 \\
\hline \multirow[t]{2}{*}{ USA } & National Institute of Standards and Technology (NIST), Gaithersburg & FG5-204 & - & - \\
\hline & Bureau International des Poids et Mesures (BIPM), Sèvres & FG5-108 & $\begin{array}{l}\text { LCR-G336, } \\
\text { belonging } \\
\text { to ORB }\end{array}$ & FG5-108 \\
\hline
\end{tabular}

The vertical gravity gradients, which are known to be non-linear at the sites of the BIPM network [9], were determined by relative $g$ measurements at heights of approximately $0.05 \mathrm{~m}$ (LCR only), $0.30 \mathrm{~m}, 0.90 \mathrm{~m}$ and $1.30 \mathrm{~m}$. The measurements at $0.30 \mathrm{~m}$ were introduced to improve the link between the Scintrex and LCR data. These gravimeters have different sensor heights: that of the Scintrex is approximately $0.26 \mathrm{~m}$ while that of the LCR is only about $0.05 \mathrm{~m}$ in its standard configuration. Five sets of tripods were constructed at the BIPM to realize the necessary heights with the various types of gravimeter. Each set consists of tripods with heights of approximately $0.25 \mathrm{~m}, 0.40 \mathrm{~m}$ and $0.60 \mathrm{~m}$, which in different combinations can form towers (supports) of all the required heights. The top plate of each support has three seats (blind holes) of depth $3 \mathrm{~mm}$ to hold the legs of a support installed above it. Each support is also equipped with a screw unit to fasten them together. Figures $3 a$ and $3 b$ show the supports assembled to hold the LCR and Scintrex sensors at different reference heights. The new supports and the additional height level improved the accuracy of the measurements of the vertical gravity gradients. Loops for gradient determinations with at least three relative measurements at each height were proposed in a similar way to that for the network tie measurements.

The majority of the relative measurements were carried out from 5 to 8 June and from 18 to 23 June 2001 , with some complementary measurements made in July 2001. In total, seventeen relative gravimeters from fourteen institutes and eight countries took part. About 2000 measurements (or occupations, as gravimetrists call them) were performed.

\subsection{Data processing}

Data processing was carried out following the standard procedure for high-precision gravimetry [2]. Preprocessing included the calculation of corrections for Earth tides and the differences of the sensor heights from the nominal reference height at each point, and the conversion of the gravimeter readings to $g$ values in milligals using the owner-supplied scale factors. Tidal corrections included the observed tidal factors as given 


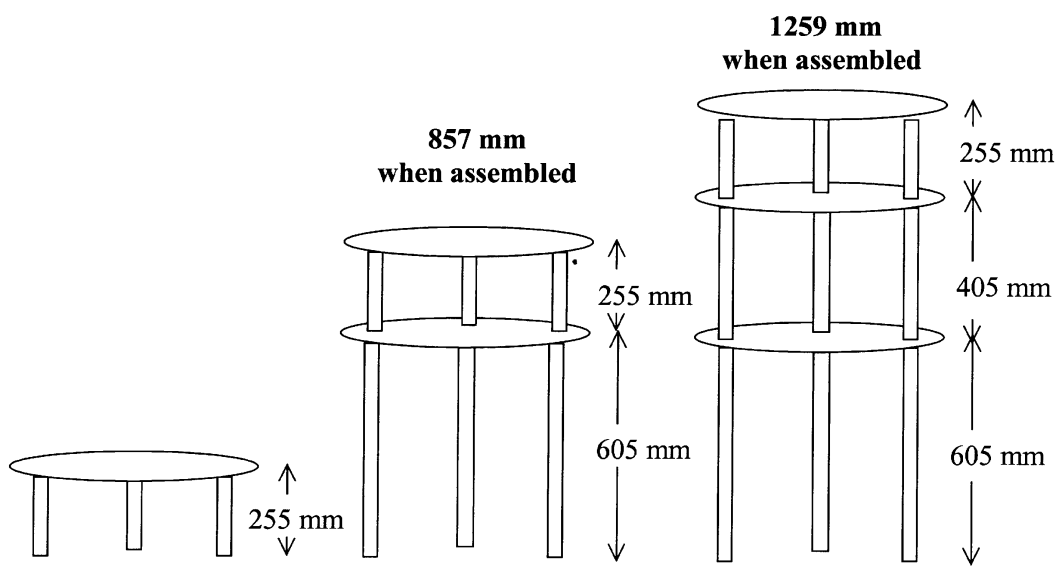

Figure 3a. Combination of tripods assembled for the LCR gravimeters (sensor height about $5 \mathrm{~cm}$ ).

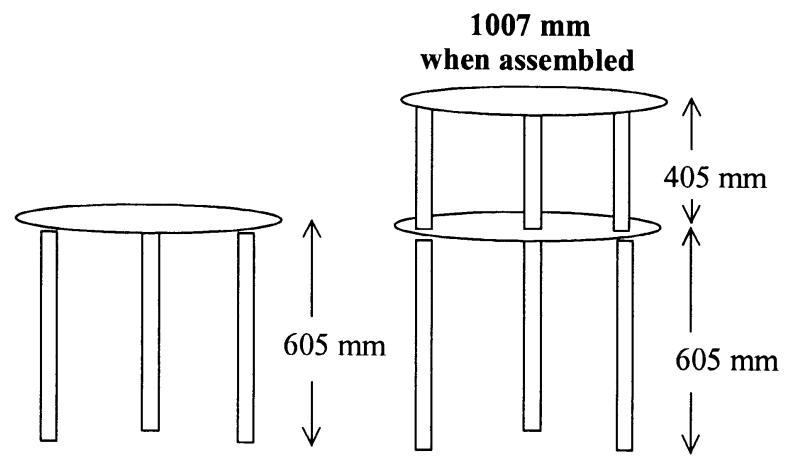

Figure 3b. Combination of tripods assembled for the Scintrex gravimeters (sensor height about $30 \mathrm{~cm}$ ).

in the database of the International Centre for Earth Tides (ICET) [9].

The corrected readings were used as the input data for two independent adjustment procedures. The first adjustment procedure was developed by Becker et al. [8] and uses a model based on the gravimeter readings. This approach was used to process the relative data in all previous ICAGs. The second approach was developed at the BIPM by Jiang et al. [14] and uses a model based on gravity differences. This approach was originally developed for the adjustment of the China Gravity Base Net 1985 System and uses the "adjG" software modified and adopted to the ICAG-2001 gravity network.

\subsubsection{Observation equations for the adjustment}

As this is the first time the "adjG" software has been used to process ICAG data, the observation equations and principles of the adjustment are summarized here. Detailed discussion of the mathematical models may be found in [14].

The observation equations for the relative measurements are obtained to adjust the differences of the gravimeter readings, omitting periodic terms as in the ICAGs. The equations may also be used for the absolute measurements if these were performed at a minimum of two points within a time interval during which the parameters and offsets of the absolute gravimeter remain stable.

The observation equations for the $g$-value differences with weights $w_{i, j}$ may be written

$$
v_{i, j}=\sum_{k=1}^{P_{k}} E_{k}\left(z_{j}^{k}-z_{i}^{k}\right)-\left(\bar{g}_{j}-\bar{g}_{i}\right),
$$

where

$w_{i, j}$ : weight of the adjusted $g$-value difference between points $i$ and $j$. For relative gravimeters the weight is firstly predetermined using analysis of the zerodrift behaviour of the closure measurements in the loop and, if necessary, modified for each $g$-value difference based on its residuals in the preadjustment. For absolute gravimeters the weight depends on their individual uncertainty and the gradient correction error.

$v_{i, j}$ : residual of the adjusted $g$-value difference between points $i$ and $j$.

$\bar{g}_{i}, \bar{g}_{j}$ : adjusted $g$ values at points $i$ and $j$.

$z_{i}, z_{j}$ : zero-drift-corrected readings of the relative gravimeter at points $i$ and $j$, or $g$ values measured using the absolute gravimeter.

$k, E_{k}$ : degree and coefficients of the polynomial of order $P_{k}$ of the gravimeter scale function. For the absolute $g$ data $E_{k}=1$ and $k=1$.

The unknowns, such as the gravity values and the parameters of the scale functions, are determined by the least-squares method of minimizing the residuals based on the observation equations. This also provides estimates of the mean square errors for all unknowns determined.

The zero-drift corrections for the relative gravimeters were applied in the pre-processing stage, whereas in the alternative adjustment according to [8] the drift determination was included in the adjustment as a whole. A polynomial model was used to estimate the zero drift of a loop measured within about 5 hours. A network loop gives about nineteen closure measurements. For the LCR and Scintrex 
gravimeters the gradient loops give thirteen and ten closure measurements, respectively. The software autodetects the required order of zero-drift polynomial from the closure number divided by five (at least five observations are required to determine an unknown polynomial coefficient in order to obtain a reasonable correction for zero drift). If there are eleven closure measurements in a loop, for example, a second-order polynomial is applied.

A polynomial of at most third order and at least first order was determined by least-squares pre-adjustment. In the case of zero-drift jumps or discontinuities, the loop to be processed was divided into two sub-loops and zero drifts were calculated separately. The mean square error of such zero-drift-free gravity readings varied from $1 \mu \mathrm{Gal}$ to $2 \mu \mathrm{Gal}$ for the gradient measurements and from $2 \mu \mathrm{Gal}$ to $5 \mu \mathrm{Gal}$ for the network measurements, for both the quartz-spring Scintrex and metal-spring LCR gravimeters.

The observation equations for $g$ values (or a single corrected absolute gravity observation) is

$$
v_{i}=z_{i}-\bar{g}_{i}+\delta_{k},
$$

where

$\bar{g}_{i}$ : adjusted $g$ value at point $i$, calculated with weight $w_{i}$.

$\delta_{k}$ : offset of the $k$-th gravimeter.

The offsets of those absolute gravimeters with larger residuals were determined in test computations. However, it was decided that for ICAG-2001 the offsets of the absolute gravimeters would not be taken into account, in order to better reveal any discrepancies between the absolute measurements. For the combined adjustment of the results of the absolute and relative measurements, $g$ values for one selected point were used according to (2); all other $g$ values as well as the relative gravimeter readings were introduced according to $(1)$.

In the calculation of the vertical gravity gradient correction, we assume that the gravity field over the sites may be represented by a second-order polynomial function of height $h$ above the benchmark:

$$
g(h)=c_{0}+c_{1} h+c_{2} h^{2},
$$

where the coefficients $c_{0}, c_{1}$ and $c_{2}$ are obtained for each site by least-squares minimization. The gradient correction $\delta_{g}$ of the $g$-value difference between the heights $h_{0}$ and $h$ is given by

$\delta_{g}=g(h)-g\left(h_{0}\right)=c_{1}\left(h-h_{0}\right)+c_{2}\left(h^{2}-h_{0}^{2}\right)$.

Equation (4) is then used to transfer the relative gravimeter readings from the sensor heights to the reference heights $h_{0}(0.05 \mathrm{~m}, 0.30 \mathrm{~m}, 0.60 \mathrm{~m}, 0.90 \mathrm{~m}$ or $1.30 \mathrm{~m}$ ) and to transfer the $g$ values measured using the absolute gravimeters from the height of the observations (the highest point of the path of the falling test body) to the standard network height of $0.90 \mathrm{~m}$.

\subsubsection{Weighting of measurement results}

A weighting scheme assuming non-correlated observations was applied and any results lying outside three times the mean standard deviation of the residuals (differences between the mean and measured values) were rejected. The weights $w_{i, j}$ lie within the limits $w_{\min } \leq w_{i, j} \leq w_{\max }$. The upper limit $w_{\max }$ was set to avoid the domination of any one gravimeter and the lower limit $w_{\min }$ ensures that all the gravimeters contribute.

Weights for $g$ value

The weight of the measured absolute $g$ value corresponding to (2) is given by

$$
w_{\mathrm{abs}, i}=\frac{\mu^{2}}{M_{i}^{2}},
$$

where $M_{i}$ is the mean square error of the measurement and $\mu=4.5 \mu \mathrm{Gal}$ is the a priori unit weight mean square error, chosen to match the assumed combined error of an absolute gravity measurement:

$$
\begin{aligned}
& M_{i}^{2}=m_{\mathrm{abs}, i}^{2}+\bar{m}_{\text {gradient }}^{2}+\bar{m}_{\mathrm{sys}}^{2}, \\
& \mu^{2}=\bar{m}_{\text {gradient }}^{2}+\bar{m}_{\mathrm{abs}}^{2}+\bar{m}_{\mathrm{sys}}^{2},
\end{aligned}
$$

where

$\bar{m}_{\text {gradient }}=0.5 \mu \mathrm{Gal}$ is the average uncertainty resulting from the gradient determination (the details of its calculation will be published in a BIPM report [15]).

$\bar{m}_{\text {abs }}=2.0 \mu \mathrm{Gal}$ is the average standard deviation of the absolute gravity measurements (excluding some of the data of the A10-003 gravimeter, see Table 5).

$\bar{m}_{\text {sys }}=4.0 \mu \mathrm{Gal}$ is the average systematic error of the absolute measurements (determined iteratively after the adjustment of (i) only the absolute data and (ii) combined adjustment of the relative and absolute data).

Here, the limit $w_{\min }=0.01$ was chosen to reduce the contribution of those measurements with large residuals. No assignment of $w_{\max }$ was necessary because the weights of all the results of absolute measurements were similar and no over-weighting of a particular gravimeter was expected.

\section{Weights for g-value differences}

The weights for the gravity differences in observation equation (1) are given by the formula

$$
w_{i, j}^{2}=\frac{\mu^{2}}{M_{i, j}^{2}},
$$


where $M_{i, j}$ is the mean square error of the corresponding gravity differences. There are two cases:

(a) For relative gravimeters, $M_{i, j}$ is estimated from the zero-drift calculation and is therefore common to all the gravimeters within a particular loop. The corresponding weight $w_{i, j}$ lies within the limits $w_{\min } \leq w_{i, j} \leq w_{\max }$, chosen to be $w_{\min }=0.1$ and $w_{\max }=4$. The upper limit, $w_{\max }$, was determined such that $n w_{\max }$, where $n$ is the total number of observations, is equal to half the total weight of the relative observations. In this way, $w_{\max }$ provides optimal reliability to the ensemble average in which the number of outlying observations (those lying outside three times the standard deviations of the residuals) is minimal.

(b) For absolute gravimeters,

$$
M_{i, j}^{2}=m_{\mathrm{abs}, i}^{2}+m_{\mathrm{abs}, j}^{2}+2 \bar{m}_{\text {gradient }}^{2},
$$

where $m_{\mathrm{abs}, i}$ and $m_{\mathrm{abs}, j}$ are the standard deviations of the $g$ values measured using the absolute gravimeters at points $i$ and $j$. A fourth-term contribution arising from systematic errors is neglected because the systematic errors for any particular gravimeter are highly correlated, which to a large extent compensates the effect of these errors.

\subsubsection{Results of adjustment}

Test computations to optimize the data-processing strategy were performed taking the following into consideration:

- accuracy, weighting of the data, discrepancies, and systematic errors and offsets of the absolute measurements;

- accuracy, weighting of the data, discrepancies and scale calibrations of the relative gravimeters;

- $\quad$ outlying data and data rejections;

- gradient corrections.

Based on these parameters, different adjustments were performed as follows.

1. Adjustment of the results of only the relative measurements. This is an unconstrained network adjustment with fixed point $\mathrm{A}$, either with or without the use of owner-supplied scales. Some well-known calibration baselines, such as the ParisOrléans absolute baseline and the Hanover vertical baseline [16], were indirectly introduced in the tests.

2. Adjustment of only the absolute measurement data.

3. Combined adjustment of both relative and absolute data.
Vertical gravity gradients above each site were approximated using second-order polynomials based on the results of adjustment 1 .

Adjustments were made using the two models outlined in Section 4.2. In theory, both models should result in the same $g$ values calculated from a common data set, assuming an adequate model for the gravimeter drift, tares and interruptions as well as for the convergence of the iterative weight determination of each measurement. In practice, however, the results of the two adjustment models differ slightly due to differences in outlier rejection levels, drift and tare models as well as in the final determination of the weights. Tests showed that the discrepancies between the two models are no greater than $1.1 \mu \mathrm{Gal}$. For the final evaluation of ICAG-2001 data it was decided to accept the differences between two independent solutions when they became less than the uncertainties of the estimated parameters. At this point the iteration in the data cleaning and model refinement was stopped.

After these tests, the second model [14] was used for the data analysis and calculation of the final results of ICAG-2001.

\section{Adjustment of the relative measurement data}

Although all the participating relative gravimeters were supposedly calibrated, a uniform scale for the relative networks was introduced implicitly during the adjustment by fixing the scales of the gravimeters G709 and G79. These gravimeters belong to the University of Hanover and were calibrated on the Hanover calibration system immediately after the relative measurements of ICAG-2001.

Table 2 presents the results of the adjustment of so-scaled relative data based on $g$-value differences and Table 3 the coefficients of the polynomials (3) representing the gravity field over the sites.

\section{Absolute measurements and combined data processing}

\subsection{Absolute measurements and reductions}

A four-point gravity network (sites A, A2, B, B1) was chosen for the absolute measurements, to allow the six ties between them to be measured at least five times. Figure 4 shows the gravity ties measured during ICAG-2001.

Gravimeters FG5-213 (Japan) and FG5-204 (USA) used the electronic timing unit belonging to the BIPM because of some troubles with their own timing electronics. The interferometer unit and laser of the gravimeter JILAg-5 (Finland) were replaced due to breakdown after the measurements at sites B and B1 and the measurement data of this gravimeter at the remaining sites $\mathrm{A}$ and $\mathrm{A} 2$ were processed as the data from a different gravimeter JILAg-5/1. The data of 
Table 2. Final results of relative measurements during ICAG-2001 (expressed in microgals after subtraction of the reference value $g_{\mathrm{r}}=980920000 \mu \mathrm{Gal}$ ), where $m$ is the mean-square error of the adjusted $g$ value relative to the fixed adjustment $g$ value at point A.090. The points are described by the site name and the height of the measurement in centimetres, e.g. A2.030 corresponds to point A2 at a height of $0.3 \mathrm{~m}$.

\begin{tabular}{|c|c|c|c|c|c|c|c|}
\hline No. & Point & Adjusted $g$ values/ $\mu \mathrm{Gal}$ & $m / \mu \mathrm{Gal}$ & No. & Point & Adjusted $g$ values $/ \mu \mathrm{Gal}$ & $m / \mu \mathrm{Gal}$ \\
\hline 1 & A.005 & 5968.2 & 0.7 & 15 & B1.090 & 8015.6 & 0.7 \\
\hline 2 & А. 030 & 5887.6 & 0.4 & 16 & B1.130 & 7901.4 & 0.8 \\
\hline 3 & A.090 & 5701.2 & 0.0 & 17 & B3.005 & 8259.7 & 1.2 \\
\hline 4 & A. 130 & 5580.4 & 0.4 & 18 & B3.030 & 8183.3 & 0.9 \\
\hline 5 & A2.005 & 5972.0 & 0.8 & 19 & B3.090 & 8002.3 & 0.8 \\
\hline 6 & A 2.030 & 5890.5 & 0.5 & 20 & B3.130 & 7886.4 & 0.9 \\
\hline 7 & A2.090 & 5706.3 & 0.4 & 21 & L3.005 & 6852.8 & 1.0 \\
\hline 8 & A2.130 & 5586.8 & 0.5 & 22 & L3.030 & 6783.4 & 0.7 \\
\hline 9 & B.005 & 8273.4 & 1.0 & 23 & L3.090 & 6618.7 & 0.5 \\
\hline 10 & B.030 & 8197.6 & 0.8 & 24 & L3.130 & 6510.8 & 0.6 \\
\hline 11 & B.090 & 8019.3 & 0.7 & 25 & L4.005 & 6868.2 & 1.1 \\
\hline 12 & B. 130 & 7900.2 & 0.7 & 26 & L4.030 & 6798.7 & 0.7 \\
\hline 13 & B1.005 & 8266.2 & 1.0 & 27 & L4.090 & 6632.8 & 0.5 \\
\hline 14 & B1.030 & 8191.0 & 0.9 & 28 & L4.130 & 6522.1 & 0.7 \\
\hline
\end{tabular}

Table 3. Polynomial coefficients for gravity field distributions over the sites and corresponding vertical gravity gradients $\gamma$ at heights $0.9 \mathrm{~m}$ and $1.2 \mathrm{~m}$.

\begin{tabular}{lllllll}
\hline & \multicolumn{3}{c}{ Coefficients } & & \multicolumn{2}{c}{ Gradients } \\
\cline { 2 - 3 } Site & $c_{0} / \mu \mathrm{Gal}$ & $c_{1} /(\mu \mathrm{Gal} / \mathrm{m})$ & $c_{2} /\left(\mu \mathrm{Gal} / \mathrm{m}^{2}\right)$ & & $\gamma(0.9 \mathrm{~m}) /(\mu \mathrm{Gal} / \mathrm{m})$ & $\gamma(1.2 \mathrm{~m}) /(\mu \mathrm{Gal} / \mathrm{m})$ \\
\hline A & 5.9847 & -322.69 & 9.8 & & -305.1 & -299.2 \\
A2 & 5.9887 & -324.14 & -300.81 & 2.1 & -301.3 & -293.7 \\
B & 8.2880 & -302.39 & 8.1 & -297.0 & -281.5 \\
B1 & 8.2801 & -310.70 & 9.0 & -287.8 & -281.0 \\
B3 & 8.2747 & -279.25 & 4.4 & -294.5 & -289.1 \\
L3 & 6.8670 & -276.51 & 0.1 & -273.3 & -268.7 \\
L4 & 6.8822 & & & -276.3 & -276.3 \\
\hline
\end{tabular}

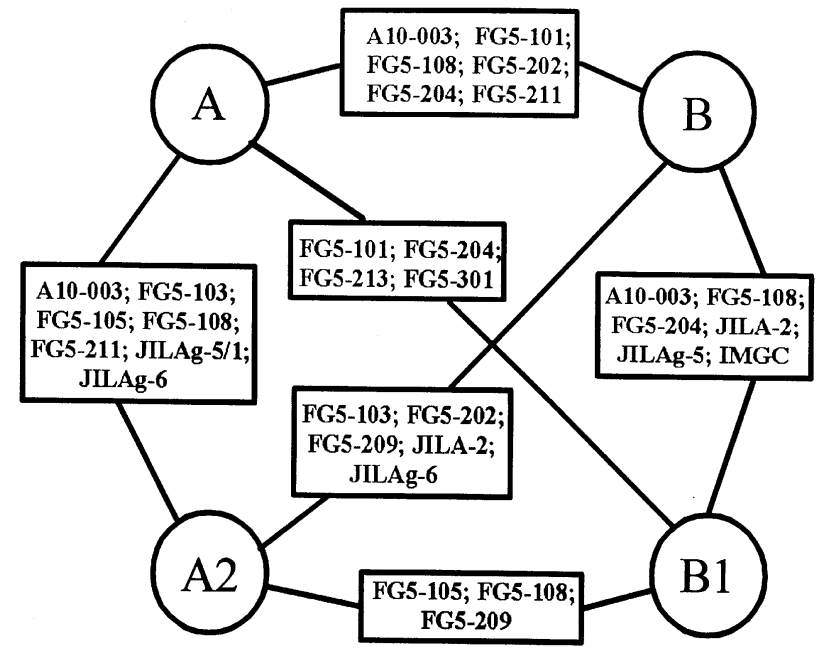

Figure 4. Diagram of the ties measured by absolute gravimeter during ICAG-2001.

A10-b002 (BKG, Germany) were not presented by the participants for processing. The data of FG5-206 were presented from only one site, B.

The first stage of the absolute data processing was reprocessing using, where possible, the same software. The new $g$ software was used for most of the instruments except FG5-105 (for which REPLAY 2.22 software was used), FG5-108 (for which a Unix version was used), FG5-213 (for which REPLAY 3.14 was used) and JILAg-6, for which REPLAY software (previous version of Micro-g Solutions software) was used. The algorithm in all versions is the same, but the format of the input data differs. For the IMGC and JILAg-5 (and JILAg-5/1) gravimeters the operators provided their own processed results.

The drop data output by these free-fall gravimeters are the space intervals determined by means of laser interferometry, and the time intervals with respect to the start of the drop (or throw) of the free-falling test body. The free-fall acceleration is then estimated by fitting the parameters in the appropriate equation of motion to these sets of data. In general, 600 scaled fringes starting at fringe 30 (see Table 4 for each gravimeter) were selected for the fitting of the equation of motion to the data. A scaled fringe corresponds to $N(\lambda / 2)$ where $N$ is the fringe scale factor (specified, for example, as 4000 in Micro-g Solutions software OLIVIA) and $\lambda$ is the nominal wavelength of the laser radiation. The start and stop fringes were selected based on the slight dependence of the resulting $g$ value. No system response correction was applied. 
Table 4. Results of all absolute measurements during ICAG-2001 (expressed in microgals after subtraction of the reference value $\left.g_{\mathrm{r}}=980920000 \mu \mathrm{Gal}\right)$.

\begin{tabular}{|c|c|c|c|c|c|c|c|c|c|c|}
\hline Date (2001) & Gravimeter & Site & $\begin{array}{l}\text { \# sets/ } \\
\text { \# drops }\end{array}$ & $\begin{array}{l}\text { Gradient } \\
\mu \mathrm{Gal} / \mathrm{cm}\end{array}$ & $Z_{\text {inst }} / \mathrm{cm}$ & $Z_{\text {ref }} / \mathrm{cm}$ & $Z_{\text {top }} / \mathrm{cm}$ & $\begin{array}{l}g \text { at } Z_{\text {top }} \\
\mu G a l\end{array}$ & $\begin{array}{l}u(\text { set }) / \\
\mu \mathrm{Gal}\end{array}$ & Fringes \\
\hline 1 & 2 & 3 & 4 & 5 & 6 & 7 & 8 & 9 & 10 & 11 \\
\hline 7-8 Jul. & A10-003 & $\mathrm{A}$ & $180 / 25$ & -3.048 & 74.9 & 6.9 & 81.8 & 5690.7 & 33.1 & $120 ; 630$ \\
\hline 27-28 Jul. & FG5-101 & A & $9 / 150$ & -2.984 & 116.4 & 13.2 & 129.6 & 5580.8 & 0.8 & $30 ; 600$ \\
\hline 28 Jul. & FG5-101 & A & $12 / 150$ & -2.984 & 116.4 & 13.2 & 129.6 & 5580.4 & 0.9 & $30 ; 600$ \\
\hline 18-19 Jul. & FG5-103 & A & $18 / 200$ & -2.984 & 80.9 & 50.0 & 130.9 & 5580.7 & 0.8 & $30 ; 600$ \\
\hline 19-20 Jul. & FG5-103 & A & $24 / 200$ & -2.984 & 80.9 & 50.0 & 130.9 & 5580.7 & 1.2 & $30 ; 600$ \\
\hline 13-15 Jul. & FG5-105 & A & $78 / 100$ & -2.984 & 80.7 & 49.4 & 130.1 & 5578.0 & 1.1 & $2 ; 90$ \\
\hline 29 Jun. & FG5-108 & A & $24 / 100$ & -2.984 & 80.6 & 49.4 & 130.0 & 5585.5 & 1.1 & $1 ; 150$ \\
\hline 19-22 Aug. & FG5-108 & A & $142 / 100$ & -2.984 & 80.6 & 49.4 & 130.0 & 5585.4 & 1.3 & $1 ; 150$ \\
\hline 25-27 Aug. & FG5-108 & A & $96 / 100$ & -2.984 & 80.6 & 49.4 & 130.0 & 5585.8 & 1.3 & $1 ; 150$ \\
\hline 20-21 Jul. & FG5-202 & A & $40 / 100$ & -2.984 & 80.7 & 49.4 & 130.1 & 5581.3 & 1.1 & $30 ; 600$ \\
\hline 10-11 Jul. & FG5-204 & A & $22 / 100$ & -2.984 & 80.7 & 49.2 & 129.8 & 5577.1 & 5.8 & $30 ; 600$ \\
\hline 15-16 Jul. & FG5-204 & A & $24 / 100$ & -2.984 & 80.7 & 49.1 & 129.7 & 5575.7 & 1.4 & $30 ; 600$ \\
\hline 2-3 Jul. & FG5-206 & $\mathrm{A}$ & $25 / 100$ & -2.984 & 80.8 & 49.4 & 130.2 & 5585.2 & 0.9 & $1 ; 150$ \\
\hline 11-12 Jul. & FG5-211 & A & $48 / 100$ & -2.984 & 116.4 & 13.3 & 129.7 & 5575.0 & 1.4 & $30 ; 600$ \\
\hline 12-13 Jul. & FG5-211 & A & $32 / 100$ & -2.984 & 116.4 & 13.1 & 129.4 & 5575.6 & 1.3 & $30 ; 600$ \\
\hline 1-2 Aug. & FG5- & A & $15 / 100$ & -2.984 & 116.3 & 11.8 & 128.1 & 5586.4 & 1.3 & $30 ; 600$ \\
\hline 28-29 Jul. & FG5-301 & A & $22 / 150$ & -2.984 & 86.1 & 13.0 & 99.1 & 5670.3 & 1.6 & $30 ; 500$ \\
\hline 22-24 Jul. & JILAg-5/1 & A & $127 / 25$ & -3.048 & -6.5 & 91.3 & 84.8 & 5723.2 & 6.2 & $1 ; 150$ \\
\hline 4-5 Jul. & JILAg-6 & A & $14 / 175$ & -3.048 & -5.5 & 97.8 & 92.3 & 5704.3 & 2.6 & $30 ; 600$ \\
\hline \multirow[t]{2}{*}{ 5-6 Jul. } & JILAg-6 & A & $18 / 175$ & -3.048 & -5.5 & 97.8 & 92.3 & 5703.7 & 3.2 & $30 ; 600$ \\
\hline & FG5 & Al & $20 / 100$ & -2.984 & 116.3 & 11.7 & 128.0 & 5571.5 & 0.8 & $30 ; 600$ \\
\hline 31 Jul.-1 Aug. & FG5-213 & Al & $14 / 100$ & -2.984 & 116.3 & 11.7 & 128.0 & 5571.0 & 0.8 & $30 ; 600$ \\
\hline 8 Jul. & A $10-003$ & $\mathrm{~A} 2$ & $50 / 25$ & -3.013 & 74.9 & 6.9 & 81.8 & 5684.6 & 22.1 & $120 ; 630$ \\
\hline 20-21 Jul. & FG5-103 & A2 & $24 / 200$ & -2.933 & 80.9 & 49.8 & 130.7 & 5587.5 & 1.1 & $30 ; 600$ \\
\hline 21-22 Jul. & FG5-103 & A2 & $20 / 200$ & -2.933 & 80.9 & 49.8 & 130.7 & 5589.0 & 1.0 & $30 ; 600$ \\
\hline 11-13 Jul. & FG5 & $\mathrm{A} 2$ & $72 / 100$ & -2.933 & 80.7 & 49.2 & 129.9 & 5583.9 & 3.6 & $2 ; 90$ \\
\hline 14 Aug. & FG5-108 & $\mathrm{A} 2$ & $22 / 100$ & -2.933 & 80.6 & 49.3 & 129.9 & 5593.2 & 1.0 & $1 ; 150$ \\
\hline 15 Aug. & FG5-108 & $\mathrm{A} 2$ & $40 / 100$ & -2.933 & 80.6 & 49.3 & 129.9 & 5594.3 & 0.9 & $1 ; 150$ \\
\hline 16 Aug. & FG5-108 & $\mathrm{A} 2$ & $26 / 100$ & -2.933 & 80.6 & 49.3 & 129.9 & 5594.2 & 1.2 & $1 ; 150$ \\
\hline $15-1$ & FG5 & $\mathrm{A} 2$ & $10 / 100$ & -2.933 & 80.7 & 49.2 & 129.9 & 5584.9 & 1.1 & $30 ; 600$ \\
\hline 16-17 Jul. & FG5 & $\mathrm{A} 2$ & $24 / 100$ & -2.933 & 80.7 & 49.2 & 129.9 & 5585.8 & 1.4 & $30 ; 600$ \\
\hline $17 \mathrm{Jul}$. & FG5-202 & $\mathrm{A} 2$ & $10 / 100$ & -2.933 & 80.7 & 49.2 & 129.9 & 5586.8 & 2.1 & $30 ; 600$ \\
\hline 17-18 Jul. & FG5-209 & $\mathrm{A} 2$ & $20 / 100$ & -2.933 & 116.3 & 12.7 & 129.0 & 5589.9 & 2.0 & $30 ; 600$ \\
\hline 18-19 Jul. & FG5-209 & $\mathrm{A} 2$ & $24 / 100$ & -2.933 & 116.3 & 12.7 & 129.0 & 5590.7 & 1.8 & 00 \\
\hline Jul. & FG5 & $\mathrm{A} 2$ & $15 / 100$ & -2.933 & 116.3 & 12.7 & 129.0 & 5589.9 & 0.9 & $30 ; 600$ \\
\hline 13-14 Jul. & FG5-211 & $\mathrm{A} 2$ & $48 / 100$ & -2.933 & 116.4 & 13.1 & 129.5 & 5576.9 & 1.0 & $30 ; 600$ \\
\hline 14-15 Jul. & FG5-211 & $\mathrm{A} 2$ & $41 / 100$ & -2.933 & 116.4 & 13.1 & 129.5 & 5576.5 & 0.7 & $30 ; 600$ \\
\hline 9-10 Jul. & JILA-2 & $\mathrm{A} 2$ & $200 / 25$ & -3.013 & 75.6 & 14.8 & 90.5 & 5695.7 & 22.8 & $60 ; 550$ \\
\hline 10 Jul. & JILA-2 & $\mathrm{A} 2$ & $30 / 25$ & -3.013 & 75.6 & 14.8 & 90.5 & 5706.7 & 25.2 & $60 ; 550$ \\
\hline 10-11 Jul. & JILA-2 & $\mathrm{A} 2$ & $127 / 25$ & -3.013 & 75.6 & 14.8 & 90.5 & 5727.0 & 27.3 & $60 ; 550$ \\
\hline 24-25 Jul. & JILAg-5/1 & $\mathrm{A} 2$ & $74 / 25$ & -3.013 & -6.5 & 90.9 & 84.4 & 5727.7 & 5.5 & $1 ; 150$ \\
\hline 6-7 Jul. & JILAg-6 & $\mathrm{A} 2$ & $22 / 175$ & -3.013 & -5.5 & 97.6 & 92.1 & 5711.8 & 2.8 & $30 ; 600$ \\
\hline 5-6 Jul. & A $10-003$ & B & $135 / 25$ & -2.957 & 74.9 & 7.2 & 82.1 & 8022.2 & 21.4 & $120 ; 630$ \\
\hline $6 \mathrm{Jul}$. & A10-003 & B & $30 / 25$ & -2.957 & 74.9 & 7.0 & 81.9 & 8005.2 & 22.2 & $120 ; 630$ \\
\hline 29-30 Jul. & FG5-101 & B & $20 / 150$ & -2.957 & 116.4 & 12.9 & 129.3 & 7909.0 & 2.0 & $30 ; 600$ \\
\hline 22-23 Jul. & FG5-103 & B & $19 / 200$ & -2.957 & 80.9 & 49.9 & 130.8 & 7895.6 & 1.3 & $30 ; 600$ \\
\hline 30 Jun. & FG5-108 & B & $24 / 100$ & -2.957 & 80.6 & 49.3 & 129.9 & 7905.4 & 1.0 & $1 ; 150$ \\
\hline 6 Aug. & FG5-108 & B & $24 / 100$ & -2.957 & 80.6 & 49.3 & 129.9 & 7905.0 & 0.7 & $1 ; 150$ \\
\hline 7 Aug. & FG5-108 & B & $24 / 100$ & -2.957 & 80.6 & 49.3 & 129.9 & 7906.2 & 1.1 & $1 ; 150$ \\
\hline 8 Aug. & FG5-108 & B & $48 / 100$ & -2.957 & 80.6 & 49.3 & 129.9 & 7906.4 & 0.9 & $1 ; 150$ \\
\hline 17-18 Jul. & FG5-202 & B & $13 / 100$ & -2.957 & 80.7 & 49.1 & 129.8 & 7903.8 & 2.4 & $30 ; 600$ \\
\hline 18-19 Jul. & FG5-202 & B & $27 / 100$ & -2.957 & 80.7 & 49.1 & 129.8 & 7900.9 & 1.8 & $30 ; 600$ \\
\hline 14-15 Jul. & FG5-204 & B & $24 / 100$ & -2.957 & 80.7 & 48.7 & 129.4 & 7897.9 & 3.0 & $30 ; 600$ \\
\hline 16-17 Jul. & FG5-209 & B & $24 / 100$ & -2.957 & 116.3 & 12.8 & 129.0 & 7902.1 & 1.3 & $30 ; 600$ \\
\hline 17 Jul. & FG5-209 & B & $9 / 100$ & -2.957 & 116.3 & 12.8 & 129.0 & 7902.2 & 1.2 & $30 ; 600$ \\
\hline 9-10 Jul. & FG5-211 & B & $30 / 100$ & -2.957 & 116.4 & 13.1 & 129.4 & 7895.7 & 0.9 & $30 ; 600$ \\
\hline 10-11 Jul. & FG5-211 & B & $48 / 100$ & -2.957 & 116.4 & 13.1 & 129.4 & 7895.9 & 1.4 & $30 ; 600$ \\
\hline
\end{tabular}


Correction for the speed of light was made using the retarded time scale

$$
\tau_{i}=t_{i}-\frac{\left(x_{i}-x_{0}\right)}{c}
$$

and the equation of motion was

$$
\begin{aligned}
& x_{i}=x_{0}\left(1+\frac{\gamma}{2} \tau^{2}\right)+v_{0}\left(\tau_{i}+\frac{\gamma}{6} \tau_{i}^{3}\right)+ \\
& \frac{g_{0}}{2}\left(\tau_{i}^{2}+\frac{\gamma}{12} \tau_{i}^{4}\right),
\end{aligned}
$$

where $c$ is the speed of light, $\left(t_{i}, x_{i}\right)$ are the time and position of the free-fall test body during a drop, $\gamma$ is the vertical gravity gradient as measured with the relative gravimeters (at $h=1.2 \mathrm{~m}$ for the FG5 gravimeters and $h=0.9 \mathrm{~m}$ for the others), and the three unknowns are $x_{0}$ (initial position), $v_{0}$ (initial velocity) and $g_{0}$ ( $g$ value at $x=0)$. At this stage the gravity gradients were calculated using preliminary results of the relative $g$ measurements [17]. We did not include here additional terms for the laser frequency modulation.

A correction of $-0.003 \mu \mathrm{Gal} / \mathrm{Pa}$ was applied to all the barometric pressure data. The barometers of the different gravimeters were compared against a BIPM pressure sensor: no individual corrections were applied because no standard calibration protocol existed. The tidal predictions were estimated using the observed

\begin{tabular}{|c|c|c|c|c|c|c|c|c|c|c|c|c|c|}
\hline No. & Grav. & $\mathrm{P}$ & $g$ & $\bar{g}$ & $\bar{g}-g$ & $\bar{u}$ & $w$ & $\widetilde{g}_{\mathrm{A}}$ & $\widetilde{g}_{\mathrm{B}}$ & $\widetilde{g}_{\mathrm{A}}-\hat{\widetilde{g}}_{\mathrm{A}}$ & $\widetilde{g}_{\mathrm{A}}-\hat{\widetilde{g}}_{\mathrm{A}, w}$ & $\widetilde{g}_{\mathrm{A}}-\hat{\tilde{g}}_{\mathrm{A}, w}^{\mathrm{P}}$ & $\widetilde{\widetilde{g}}_{\mathrm{grav}, \mathrm{A}} \pm \sigma_{\hat{g}} ; \hat{\varepsilon}$ \\
\hline 1 & 2 & 3 & 4 & 5 & 6 & 7 & 8 & 9 & 10 & 11 & 12 & 13 & 14 \\
\hline 1_1 & A10-003 & A.090 & 5665.6 & 5700.5 & 34.9 & 0.8 & 0.02 & 5665.6 & 7983.4 & -32.9 & -34.9 & -36.1 & $5669.7 \pm 12.3$ \\
\hline 1_2 & A10-003 & A2.090 & 5659.8 & 5706.2 & 46.3 & 0.9 & 0.04 & 5654.2 & 7972.0 & -44.3 & -46.3 & -46.1 & -30.8 \\
\hline 1_3 & A10-003 & B.090 & 7995.7 & 8018.3 & 22.7 & 0.8 & 0.08 & 5677.9 & 7995.7 & -20.6 & -22.6 & -23.3 & \\
\hline 1_4 & A10-003 & B1.090 & 7994.4 & 8013.8 & 19.4 & 0.9 & 0.09 & 5681.1 & 7998.9 & -17.4 & -19.4 & -17.0 & \\
\hline 2_1 & FG5-101 & A. 090 & 5699.8 & 5700.5 & 0.8 & 0.8 & 1.16 & 5699.8 & 8017.5 & 1.3 & -0.7 & -1.9 & $5703.4 \pm 4.0$ \\
\hline $2 \_3$ & FG5-101 & B.090 & 8025.5 & 8018.3 & -7.2 & 0.8 & 0.97 & 5707.7 & 8025.5 & 9.2 & 7.2 & 6.5 & 2.9 \\
\hline 2_4 & FG5-101 & B1.090 & 8016.0 & 8013.8 & -2.2 & 0.9 & 1.08 & 5702.7 & 8020.5 & 4.2 & 2.2 & 4.6 & \\
\hline 3_1 & FG5-103 & A.090 & 5703.7 & 5700.5 & -3.2 & 0.8 & 1.15 & 5703.7 & 8021.5 & 5.2 & 3.2 & 2.0 & $5701.7 \pm 2.7$ \\
\hline 3_2 & FG5-103 & A2.090 & 5708.6 & 5706.2 & -2.4 & 0.9 & 1.13 & 5702.9 & 8020.7 & 4.4 & 2.4 & 2.6 & 1.2 \\
\hline $3 \_3$ & FG5-103 & B.090 & 8016.4 & 8018.3 & 1.9 & 0.8 & 1.07 & 5698.6 & 8016.4 & 0.1 & -1.9 & -2.6 & \\
\hline 4_1 & FG5-105 & A.090 & 5698.7 & 5700.5 & 1.8 & 0.8 & 1.11 & 5698.7 & 8016.5 & 0.2 & -1.8 & -3.0 & $5698.5=$ \\
\hline 4_2 & FG5-105 & A2.090 & 5702.1 & 5706.2 & 4.1 & 0.9 & 0.69 & 5696.4 & 8014.2 & -2.1 & -4.1 & -3.9 & -2.0 \\
\hline 4_4 & FG5-105 & B1.090 & 8013.7 & 8013.8 & 0.1 & 0.9 & 0.75 & 5700.4 & 8018.2 & 1.9 & -0.1 & 2.3 & \\
\hline $5 \_1$ & FG5-108 & A. 090 & 5705.9 & 5700.5 & -5.4 & 0.8 & 1.16 & 5705.9 & 8023.7 & 7.4 & 5.4 & 4.2 & $5705.9 \pm 0.7$ \\
\hline $5 \_2$ & FG5-108 & A2.090 & 5712.2 & 5706.2 & -6.0 & 0.9 & 1.16 & 5706.5 & 8024.3 & 8.0 & 6.0 & 6.2 & 5.4 \\
\hline $5 \_3$ & FG5-108 & B.090 & 8024.2 & 8018.3 & -5.9 & 0.8 & 1.17 & 5706.4 & 8024.2 & 7.9 & 5.9 & 5.2 & \\
\hline $5 \_4$ & FG5-108 & B1.090 & 8018.2 & 8013.8 & -4.4 & 0.9 & 1.15 & 5704.9 & 8022.7 & 6.4 & 4.4 & 6.8 & \\
\hline 6_1 & FG5-202 & А.090 & 5701.9 & 5700.5 & -1.4 & 0.8 & 1.11 & 5701.9 & 8019.7 & 3.4 & 1.4 & 0.2 & $5700.8 \pm 2.1$ \\
\hline 6_2 & FG5-202 & A2.090 & 5704.0 & 5706.2 & 2.2 & 0.9 & 1.12 & 5698.3 & 8016.1 & -0.2 & -2.2 & -2.0 & 0.3 \\
\hline $6 \_3$ & FG5-202 & B.090 & 8019.9 & 8018.3 & -1.6 & 0.8 & 1.02 & 5702.1 & 8019.9 & 3.6 & 1.6 & 0.9 & \\
\hline 7_1 & FG5-204 & A.090 & 5696.0 & 5700.5 & 4.5 & 0.8 & 0.8 & 5696.0 & 8013.8 & -2.5 & -4.5 & -5.7 & $5695.9 \pm 1.0$ \\
\hline 7_3 & FG5-204 & B.090 & 8014.6 & 8018.3 & 3.7 & 0.8 & 0.79 & 5696.8 & 8014.6 & -1.7 & -3.7 & -4.4 & -4.6 \\
\hline 7_4 & FG5-204 & B1.090 & 8008.1 & 8013.8 & 5.7 & 0.9 & 0.61 & 5694.8 & 8012.6 & -3.7 & -5.7 & -3.3 & \\
\hline $8 \_1$ & FG5-206 & A. 090 & 5706.1 & 5700.5 & -5.6 & 0.8 & 1.13 & 5706.1 & 8023.9 & 7.6 & 5.6 & 4.4 & $5706.1 ; 5.6$ \\
\hline 9_2 & FG5-209 & A2.090 & 5705.0 & 5706.2 & 1.2 & 0.9 & 1.12 & 5699.3 & 8017.1 & 0.8 & -1.2 & -1.0 & $5699.4 \pm 0.6$ \\
\hline 9_3 & FG5-209 & B.090 & 8017.8 & 8018.3 & 0.5 & 0.8 & 1.13 & 5700.0 & 8017.8 & 1.5 & -0.5 & -1.2 & -1.1 \\
\hline 9_4 & FG5-209 & B1.090 & 8012.2 & 8013.8 & 1.6 & 0.9 & 1.08 & 5698.9 & 8016.7 & 0.4 & -1.6 & 0.8 & \\
\hline 10_1 & FG5-211 & А.090 & 5694.6 & 5700.5 & 5.9 & 0.8 & 1.12 & 5694.6 & 8012.4 & -3.9 & -5.9 & -7.1 & $5692.4 \pm 4.0$ \\
\hline 10_2 & FG5-211 & A2.090 & 5693.5 & 5706.2 & 12.7 & 0.9 & 1.15 & 5687.8 & 8005.6 & -10.7 & -12.7 & -12.5 & -8.1 \\
\hline $10 \_3$ & FG5-211 & B.090 & 8012.6 & 8018.3 & 5.7 & 0.8 & 1.13 & 5694.8 & 8012.6 & -3.7 & -5.7 & -6.4 & \\
\hline 11_1 & FG5-213 & A.090 & 5701.0 & 5700.5 & -0.5 & 0.8 & 1.09 & 5701.0 & 8018.8 & 2.5 & 0.5 & -0.7 & $5699.0 \pm 2.9$ \\
\hline 11_4 & FG5-213 & B1.090 & 8010.2 & 8013.8 & 3.6 & 0.9 & 1.17 & 5696.9 & 8014.7 & -1.6 & -3.6 & -1.2 & -1.5 \\
\hline 12_1 & FG5-301 & A.090 & 5698.0 & 5700.5 & 2.5 & 0.8 & 1.03 & 5698.0 & 8015.8 & -0.5 & -2.5 & -3.7 & $5696.1 \pm 2.8$ \\
\hline $12 \_4$ & FG5-301 & B1.090 & 8007.4 & 8013.8 & 6.4 & 0.9 & 1.00 & 5694.1 & 8011.9 & -4.4 & -6.4 & -4.0 & -4.5 \\
\hline 13_2 & JILA-2 & A2.090 & 5709.2 & 5706.2 & -3.0 & 0.9 & 0.07 & 5703.5 & 8021.3 & 5.0 & 3.0 & 3.2 & $5702.0 \pm 7.3$ \\
\hline $13 \_3$ & JILA-2 & B.090 & 8026.2 & 8018.3 & -7.9 & 0.8 & 0.2 & 5708.4 & 8026.2 & 9.9 & 7.9 & 7.2 & 1.5 \\
\hline $13 \_4$ & JILA-2 & B1.090 & 8007.3 & 8013.8 & 6.5 & 0.9 & 0.46 & 5694.0 & 8011.8 & -4.5 & -6.5 & -4.1 & \\
\hline 14_1 & JILAg-5/1 & A.090 & 5707.3 & 5700.5 & -6.8 & 0.8 & 0.38 & 5707.3 & 8025.1 & 8.8 & 6.8 & 5.6 & $5706.2 \pm 1.6$ \\
\hline 14_2 & JILAg-5/1 & A2.090 & 5710.8 & 5706.2 & -4.6 & 0.9 & 0.44 & 5705.1 & 8022.9 & 6.6 & 4.6 & 4.8 & 5.7 \\
\hline $15 \_3$ & JILAg-5 & B.090 & 8032.5 & 8018.3 & -14.2 & 0.8 & 0.51 & 5714.7 & 8032.5 & 16.2 & 14.2 & 13.5 & $5714.9 \pm 0.2$ \\
\hline $15 \_4$ & + JILAg-5 & B1.090 & 8028.3 & 8013.8 & -14.5 & 0.9 & 0.30 & 5715.0 & 8032.8 & 16.5 & 14.5 & 16.9 & 14.4 \\
\hline 16_1 & JILAg-6 & A.090 & 5711.0 & 5700.5 & -10.5 & 0.8 & 0.95 & 5711.0 & 8028.8 & 12.5 & 10.5 & 9.3 & $5711.2 \pm 1.3$ \\
\hline $16 \_2$ & JILAg-6 & A2.090 & 5718.2 & 5706.2 & -12.0 & 0.9 & 0.82 & 5712.5 & 8030.3 & 14.0 & 12.0 & 12.2 & 10.7 \\
\hline $16 \_3$ & JILAg-6 & B.090 & 8027.8 & 8018.3 & -9.5 & 0.8 & 0.95 & 5710.0 & 8027.8 & 11.5 & 9.5 & 8.8 & \\
\hline 17_3 & IMGC & B.090 & 8005.7 & 8018.3 & 12.6 & 0.8 & 0.98 & 5687.9 & 8005.7 & -10.6 & -12.6 & -13.3 & $5688.4 \pm 0.7$ \\
\hline 17_4 & IMGC & B1.090 & 8002.2 & 8013.8 & 11.6 & 0.9 & 0.98 & 5688.9 & 8006.7 & -9.6 & -11.6 & -9.2 & -12.1 \\
\hline
\end{tabular}

Table 5a. Results (expressed in microgals after subtraction of the reference value $980920000 \mu \mathrm{Gal}$ ) of the combined adjustment of absolute and relative measurement data during ICAG-2001 for all the absolute gravimeters. 
Table 5b. Results of the measurements (expressed in microgals after subtraction of the reference value $980920000 \mu \mathrm{Gal})$ transferred to sites $\mathrm{A}$ and $\mathrm{B}$ at $0.9 \mathrm{~m}$.

\begin{tabular}{|c|c|c|c|}
\hline \multicolumn{4}{|c|}{ Transfer to A } \\
\hline \multicolumn{2}{|c|}{ Unweighted mean } & \multicolumn{2}{|c|}{ Weighted mean } \\
\hline$\overline{\hat{\tilde{g}}_{\mathrm{A}}}$ & $5698.5 \pm 11.5$ & $\hat{\tilde{g}}_{\mathrm{A}, w}$ & $5700.5 \pm 6.6$ \\
\hline$\hat{\vec{g}}_{\mathrm{A}}^{\mathrm{A}}$ & $5699.2 \pm 10.8$ & $\hat{\widetilde{g}}_{\mathrm{A}, w}^{\mathrm{A}}$ & $5701.7 \pm 4.9$ \\
\hline$\hat{\tilde{g}}_{\mathrm{A}}^{\mathrm{A} 2}$ & $5696.6 \pm 16.0$ & $\hat{\widetilde{g}}_{\mathrm{A}, w}^{\mathrm{A} 2}$ & $5700.3 \pm 7.8$ \\
\hline$\hat{\vec{g}}_{\mathrm{A}}^{\mathrm{B}}$ & $5700.4 \pm 9.8$ & $\hat{\tilde{g}}_{\mathrm{A}, w}^{\mathrm{B}}$ & $5701.2 \pm 7.4$ \\
\hline$\hat{\tilde{g}}_{\mathrm{A}}^{\mathrm{B} 1}$ & $5697.4 \pm 8.9$ & $\hat{\tilde{g}}_{\mathrm{A}, w}^{\mathrm{B} 1}$ & $5698.1 \pm 6.4$ \\
\hline \multicolumn{4}{|c|}{ Transfer to B } \\
\hline \multicolumn{2}{|c|}{ Unweighted mean } & \multicolumn{2}{|c|}{ Weighted mean } \\
\hline$\overline{\tilde{\tilde{g}}_{\mathrm{B}}}$ & $8016.3 \pm 11.5$ & $\hat{\tilde{g}}_{\mathrm{B}, w}$ & $8018.3 \pm 6.6$ \\
\hline$\hat{\widetilde{g}}_{\mathrm{B}}^{\mathrm{A}}$ & $8017.0 \pm 10.8$ & $\hat{\tilde{g}}_{\mathrm{B}, w}^{\mathrm{A}}$ & $8019.5 \pm 4.9$ \\
\hline$\hat{\tilde{g}}_{\mathrm{B}}^{\mathrm{A} 2}$ & $8014.4 \pm 16.0$ & $\hat{\tilde{g}}_{\mathrm{B}, w}^{\mathrm{A} 2}$ & $8018.1 \pm 7.8$ \\
\hline$\hat{\vec{g}}_{\mathrm{B}}^{\mathrm{B}}$ & $8018.2 \pm 9.8$ & $\hat{\tilde{g}}_{\mathrm{B}, w}^{\mathrm{B}}$ & $8019.0 \pm 7.4$ \\
\hline$\hat{\vec{g}}_{\mathrm{B}}^{\mathrm{B} 1}$ & $8015.2 \pm 8.9$ & $\hat{\tilde{g}}_{\mathrm{B}, w}^{\mathrm{B} 1}$ & $8015.9 \pm 6.4$ \\
\hline
\end{tabular}

Table 5c. Unweighted and weighted means of the results of the measurement at each site at $0.9 \mathrm{~m}$ (expressed in microgals after subtraction of the reference value $980920000 \mu \mathrm{Gal})$.

\begin{tabular}{llll}
\hline \multicolumn{2}{l}{ Unweighted mean } & \multicolumn{2}{l}{ Weighted mean } \\
\hline$\hat{\tilde{g}}_{\mathrm{A}}^{\mathrm{A}}$ & $5699.2 \pm 10.8$ & $\hat{\tilde{g}}_{\mathrm{A}, w}^{\mathrm{A}}$ & $5701.7 \pm 4.9$ \\
$\hat{\tilde{g}}_{\mathrm{A} 2}^{\mathrm{A} 2}$ & $5702.3 \pm 16.0$ & $\hat{\hat{g}}_{\mathrm{A} 2, w}^{\mathrm{A} 2}$ & $5706.2 \pm 7.8$ \\
$\hat{\tilde{g}}_{\mathrm{B}}^{\mathrm{B}}$ & $8018.2 \pm 9.8$ & $\hat{\hat{g}}_{\mathrm{B}, w}^{\mathrm{B}}$ & $8019.0 \pm 7.4$ \\
$\hat{\vec{g}}_{\mathrm{B} 1}^{\mathrm{B} 1}$ & $8010.7 \pm 8.9$ & $\hat{\hat{g}}_{\mathrm{B} 1, w}$ & $8011.4 \pm 6.4$ \\
\hline
\end{tabular}

tidal parameters for Sèvres, provided by the ICET [9]. These observed parameters include solid Earth tides and attraction and loading effects from the ocean tides, obtained from an analysis of 292 days of data recorded at the BIPM from 6 May 1974 to 24 July 1977 using a LaCoste-Romberg spring gravimeter. The laser frequencies were measured by beat frequency measurements against one of the BIPM's reference $\mathrm{He}-\mathrm{Ne} / \mathrm{I}_{2}$ lasers. The rubidium clock frequencies were referred to a local caesium clock using an SRS620/1 frequency counter in frequency mode.

The absolute $g$ results for all the gravimeters and all the sites are presented in Table 4. For each gravimeter the mean $g$ values at height $Z_{\text {top }}$ (column 9 in Table 4) were then transferred to a height of $0.9 \mathrm{~m}$ over the sites using the polynomials for the gravity field distributions (see (3) and Table 3).

\subsection{Combined adjustment and results}

The transferred $g$ values were used for the combined adjustment of the absolute and relative data. The results of absolute measurements at site $\mathrm{A}$ were introduced according to (2); all other absolute results were introduced according to (1) in the form of differences, as for the relative data. The results of two alternative adjustments are presented in various forms in Tables $5 \mathrm{a}$ to $5 \mathrm{c}$ and Tables $6 \mathrm{a}$ to $6 \mathrm{c}$, respectively.

Tables $5 \mathrm{a}$ to $5 \mathrm{c}$ represent the results of a combined adjustment of all the relative and absolute data, including the weighted and unweighted means at sites $\mathrm{A}$ and $\mathrm{B}$. Tables $6 \mathrm{a}$ to $6 \mathrm{c}$ omit the data from some of the absolute gravimeters. The results of gravimeter A10-003 at sites A and A2 were rejected because, as can be seen in Tables $5 \mathrm{a}$ and $5 \mathrm{~b}$, the residuals at these sites (differences between the adjusted and measured $g$ values at $0.90 \mathrm{~m})$ are greater than three times $11.5 \mu \mathrm{Gal}$ (the standard deviation of the differences between the $g$ values transferred to site A at $0.90 \mathrm{~m}$ and their unweighted mean). The data of FG5-301 were omitted because these results were processed with an unexplained shift of $17 \mu \mathrm{Gal}$ recommended by the manufacturer. The data from the JILAg-5 and IMGC gravimeters were omitted in Tables $6 \mathrm{a}$ to $6 \mathrm{c}$ because the raw data of their measurements were not presented.

The following symbols are used in these tables:

No.: number of the measurement, defined as the number of the gravimeter and point number.

Grav.: type and serial number of the absolute gravimeter.

P: point for which the $g$ value is given, defined as the site and the height of the point in centimetres.

$g: g$ value transferred from height $Z_{\text {top }}$ (Table 4, column 9) to the point $0.90 \mathrm{~m}$ above the plug of the ground disk at the site. This transfer is calculated using the corresponding polynomials representing $g$ as a function of height.

$\bar{g}: g$ value obtained by combined adjustment.

$\bar{g}-g$ : residuals of adjusted $g$ values.

$\bar{u}$ : least-squares error of $\bar{g}$.

$w$ : weight of $g$ value in the combined adjustment, calculated as described in Section 4.2.2.

$\widetilde{g}_{\mathrm{A}}: g$ value transferred to point $\mathrm{A}$ at a height of $0.90 \mathrm{~m}$ using the $g$ difference obtained by the combined adjustment.

$\widetilde{g}_{\mathrm{B}}: g$ value transferred to point $\mathrm{B}$ at a height of $0.90 \mathrm{~m}$ using the $g$ difference obtained by the combined adjustment.

$\widetilde{g}_{\mathrm{A}}-\widehat{\tilde{g}}_{\mathrm{A}}$ : difference between $\widetilde{g}_{\mathrm{A}}$ and the unweighted mean value $\hat{\widetilde{g}}_{\mathrm{A}}$, averaged over all the $\widetilde{g}_{\mathrm{A}}$.

$\widetilde{g}_{\mathrm{A}}-\hat{\widetilde{g}}_{\mathrm{A}, w}$ : difference between $\widetilde{g}_{\mathrm{A}}$ and the weighted mean value $\hat{\widetilde{g}}_{\mathrm{A}, w}$, averaged over all the $\widetilde{g}_{\mathrm{A}}$.

$\widetilde{g}_{\mathrm{A}}-\hat{\tilde{g}}_{\mathrm{A}, w}$ : differences between $\widetilde{g}_{\mathrm{A}}$ and the weighted mean $\hat{\widetilde{g}}_{\mathrm{A}, w}^{\mathrm{P}}$, averaged with the weights $w$ over the data transferred from the given point $\mathrm{P}(\mathrm{P}=\mathrm{A} 2$, $\mathrm{B}, \mathrm{B} 1)$ to $\mathrm{A}$ or measured at $\mathrm{A}\left(\hat{\widetilde{g}}_{\mathrm{A}, w}^{\mathrm{A}}\right)$

$\hat{\widetilde{g}}_{\text {grav }, \mathrm{A}} \pm \sigma_{\hat{g}}$; $\hat{\varepsilon}$ : unweighted mean values of $\widetilde{g}_{\mathrm{A}}$ for each absolute gravimeter, and its standard deviation $\sigma_{\hat{g}}$; the difference $\hat{\varepsilon}$ between $\hat{\widetilde{g}}_{\text {grav }, \mathrm{A}}$ and the 
Table 6a. Results (expressed in microgals after subtraction of the reference value $980920000 \mu \mathrm{Gal}$ ) of the combined adjustment of absolute and relative measurement data during ICAG-2001, omitting the data from gravimeters

IMGC, FG5-301 and JILAg-5 and the data of A10-003 at A, A2.

\begin{tabular}{|c|c|c|c|c|c|c|c|c|c|c|c|c|c|}
\hline No. & Grav. & $\mathrm{P}$ & $g$ & $\bar{g}$ & $\bar{g}-g$ & $\bar{u}$ & $w$ & $\widetilde{g}_{\mathrm{A}}$ & $\widetilde{g}_{\mathrm{B}}$ & $\widetilde{g}_{\mathrm{A}}-\hat{\widetilde{g}}_{\mathrm{A}}$ & $\widetilde{g}_{\mathrm{A}}-\hat{\widetilde{g}}_{\mathrm{A}, w}$ & $\widetilde{g}_{\mathrm{A}}-\hat{\tilde{g}}_{\mathrm{A}, w}^{\mathrm{P}}$ & $\hat{\tilde{g}}_{\mathrm{grav}, \mathrm{A}} \pm \sigma_{\hat{g}} ; \hat{\varepsilon}$ \\
\hline$\overline{1}$ & 2 & 3 & 4 & 5 & 6 & 7 & 8 & 9 & 10 & 11 & 12 & 13 & 14 \\
\hline $1 \_3$ & A10-003 & B.090 & 7995.7 & 8018.8 & 23.1 & 0.9 & 0.08 & 5678.1 & 7995.7 & -22.1 & -23.1 & -24.0 & $5679.6 \pm 2.1$ \\
\hline $1 \_4$ & A10-003 & B1.090 & 7994.4 & 8014.5 & 20.1 & 0.9 & 0.09 & 5681.1 & 7998.7 & -19.1 & -20.1 & -18.3 & -21.6 \\
\hline $2 \_1$ & FG5-101 & A.090 & 5699.8 & 5701.2 & 1.5 & 0.9 & 1.16 & 5699.8 & 8017.4 & -0.4 & -1.4 & -2.1 & $5703.5 \pm 4.1$ \\
\hline $2 \_3$ & FG5-101 & B.090 & 8025.5 & 8018.8 & -6.7 & 0.9 & 0.97 & 5707.9 & 8025.5 & 7.7 & 6.7 & 5.8 & 2.3 \\
\hline $2 \_4$ & FG5-101 & B1.090 & 8016.0 & 8014.5 & -1.5 & 0.9 & 1.08 & 5702.7 & 8020.3 & 2.5 & 1.5 & 3.3 & \\
\hline 3 & FG5-103 & A. 090 & 5703.7 & 5701.2 & -2.5 & 0.9 & 1.15 & 5703.7 & 8021.3 & 3.5 & 2.5 & 1.8 & $5701.9 \pm 2.7$ \\
\hline $3 \_3$ & FG5-103 & A2.090 & 5708.6 & 5706.6 & -2.0 & 0.9 & 1.13 & 5703.2 & 8020.8 & 3.0 & 2.0 & 2.6 & 0.7 \\
\hline $3 \_4$ & FG5-103 & B. 090 & 8016.4 & 8018.8 & 2.4 & 0.9 & 1.07 & 5698.8 & 8016.4 & -1.4 & -2.4 & -3.3 & \\
\hline 4_1 & FG5-105 & A. 090 & 5698.7 & 5701.2 & 2.5 & 0.9 & 1.11 & 5698.7 & 8016.3 & -1.5 & -2.5 & -3.2 & $5698.6 \pm 1.9$ \\
\hline $4 \_2$ & FG5-105 & A2.090 & 5702.1 & 5706.6 & 4.5 & 0.9 & 0.69 & 5696.7 & 8014.3 & -3.5 & -4.5 & -3.9 & -2.6 \\
\hline $4 \_3$ & FG5-105 & B1.090 & 8013.7 & 8014.5 & 0.8 & 0.9 & 0.75 & 5700.4 & 8018.0 & 0.2 & -0.8 & 1.0 & \\
\hline $5 \_1$ & FG5-108 & A. 090 & 5705.9 & 5701.2 & -4.7 & 0.9 & 1.16 & 5705.9 & 8023.5 & 5.7 & 4.7 & 4.0 & $5706.1 \pm 0.9$ \\
\hline $5 \_2$ & FG5-108 & A2.090 & 5712.2 & 5706.6 & -5.6 & 0.9 & 1.16 & 5706.8 & 8024.4 & 6.6 & 5.6 & 6.2 & 4.8 \\
\hline $5 \_3$ & FG5-108 & B.090 & 8024.2 & 8018.8 & -5.4 & 0.9 & 1.17 & 5706.6 & 8024.2 & 6.4 & 5.4 & 4.5 & \\
\hline $5 \_4$ & FG5-108 & B1.090 & 8018.2 & 8014.5 & -3.7 & 0.9 & 1.15 & 5704.9 & 8022.5 & 4.7 & 3.7 & 5.5 & \\
\hline $6 \_1$ & FG5-202 & А. 090 & 5701.9 & 5701.2 & -0.7 & 0.9 & 1.11 & 5701.9 & 8019.5 & 1.7 & 0.7 & 0.0 & $5700.9 \pm 2.0$ \\
\hline $6 \_2$ & FG5-202 & A2.090 & 5704.0 & 5706.6 & 2.6 & 0.9 & 1.12 & 5698.6 & 8016.2 & -1.6 & -2.6 & -2.0 & -0.3 \\
\hline $6 \_3$ & FG5-202 & B. 090 & 8019.9 & 8018.8 & -1.1 & 0.9 & 1.02 & 5702.3 & 8019.9 & 2.1 & 1.1 & 0.2 & \\
\hline 7_1 & FG5-204 & A.090 & 5696.0 & 5701.2 & 5.2 & 0.9 & 0.80 & 5696.0 & 8013.6 & -4.2 & -5.2 & -5.9 & $5695.9 \pm 1.1$ \\
\hline 7_3 & FG5-204 & B.090 & 8014.6 & 8018.8 & 4.2 & 0.9 & 0.79 & 5697.0 & 8014.6 & -3.2 & -4.2 & -5.1 & -5.3 \\
\hline 7_4 & FG5-204 & B1.090 & 8008.1 & 8014.5 & 6.4 & 0.9 & 0.61 & 5694.8 & 8012.4 & -5.4 & -6.4 & -4.6 & \\
\hline 8_1 & FG5-206 & A. 090 & 5706.1 & 5701.2 & -4.9 & 0.9 & 1.13 & 5706.1 & 8023.7 & 5.9 & 4.9 & 4.2 & $5706.1 ; 4.9$ \\
\hline 9_2 & FG5-209 & A2.090 & 5705.0 & 5706.6 & 1.6 & 0.9 & 1.12 & 5699.6 & 8017.2 & -0.6 & -1.6 & -1.0 & $5699.6 \pm 0.7$ \\
\hline $9 \_3$ & FG5-209 & В.090 & 8017.8 & 8018.8 & 1.0 & 0.9 & 1.13 & 5700.2 & 8017.8 & 0.0 & -1.0 & -1.9 & -1.6 \\
\hline 9_4 & FG5-209 & B1.090 & 8012.2 & 8014.5 & 2.3 & 0.9 & 1.08 & 5698.9 & 8016.5 & -1.3 & -2.3 & -0.5 & \\
\hline 10_1 & FG5-211 & A. 090 & 5694.6 & 5701.2 & 6.6 & 0.9 & 1.12 & 5694.6 & 8012.2 & -5.6 & -6.6 & -7.3 & $5692.6 \pm 3.9$ \\
\hline 10_2 & FG5-211 & A2.090 & 5693.5 & 5706.6 & 13.1 & 0.9 & 1.15 & 5688.1 & 8005.7 & -12.1 & -13.1 & -12.5 & -8.6 \\
\hline $10 \_3$ & FG5-211 & B.090 & 8012.6 & 8018.8 & 6.2 & 0.9 & 1.13 & 5695.0 & 8012.6 & -5.2 & -6.2 & -7.1 & \\
\hline $11 \_1$ & FG5-213 & A.090 & 5701.0 & 5701.2 & 0.2 & 0.9 & 1.09 & 5701.0 & 8018.6 & 0.8 & -0.2 & -0.9 & $5699.0 \pm 2.9$ \\
\hline $11 \_3$ & FG5-213 & B1.090 & 8010.2 & 8014.5 & 4.3 & 0.9 & 1.17 & 5696.9 & 8014.5 & -3.3 & -4.3 & -2.5 & -2.2 \\
\hline $13 \_2$ & JILA-2 & A2.090 & 5709.2 & 5706.6 & -2.6 & 0.9 & 0.07 & 5703.8 & 8021.4 & 3.6 & 2.6 & 3.2 & $5702.1 \pm 7.4$ \\
\hline 13_3 & JILA-2 & B.090 & 8026.2 & 8018.8 & -7.4 & 0.9 & 0.20 & 5708.6 & 8026.2 & 8.4 & 7.4 & 6.5 & 0.9 \\
\hline $13 \_4$ & JILA-2 & B1.090 & 8007.3 & 8014.5 & 7.2 & 0.9 & 0.46 & 5694.0 & 8011.6 & -6.2 & -7.2 & -5.4 & \\
\hline 16_1 & JILAg-6 & A.090 & 5711.0 & 5701.2 & -9.8 & 0.9 & 0.95 & 5711.0 & 8028.6 & 10.8 & 9.8 & 9.1 & $5711.3 \pm 1.3$ \\
\hline $16 \_2$ & JILAg-6 & A2.090 & 5718.2 & 5706.6 & -11.5 & 0.9 & 0.82 & 5712.8 & 8030.3 & 12.6 & 11.6 & 12.2 & 10.1 \\
\hline $16 \_3$ & JILAg-6 & B.090 & 8027.8 & 8018.8 & -9.0 & 0.9 & 0.95 & 5710.2 & 8027.8 & 10.0 & 9.0 & 8.1 & \\
\hline
\end{tabular}

weighted mean value $\hat{\widetilde{g}}_{\mathrm{A}, w}=5700.5 \mu \mathrm{Gal}$ of all the $\widetilde{g}_{\mathrm{A}}$ in Table 5 , and the weighted mean value $\hat{\widetilde{g}}_{\mathrm{A}, w}=5701.2 \mu \mathrm{Gal}$ of all the $\widetilde{g}_{\mathrm{A}}$ in Table 6 .

Table 7 compares the results of different versions of the adjustment of relative and absolute data. Here, "adj $i$ " designates:

- $\quad$ adj1: combined adjustment of weighted absolute and relative data with some omitted data, as in the calculation of Table 6;

- $\quad \operatorname{adj2:~combined~adjustment~of~all~weighted~absolute~}$ and relative data, as in the calculation of Table 5;

- $\quad$ adj3: adjustment of only unweighted absolute data of all the absolute gravimeters;

- $\quad$ adj4: adjustment of only weighted absolute data of all the absolute gravimeters;

- $\quad$ adj5: adjustment of only weighted absolute data with some omitted gravimeters, as in the calculation of Table 6;
- adj6: adjustment of relative data only (Table 2) where the Hanover vertical calibration scale was used [16].

$\Delta_{1, i}^{\mathrm{P}}$ is the difference between the results obtained for point P using adjustments "adj1" and "adj $i$ ", where $i=2,3,4,5,6$.

Table 8 presents the results of adjustment "adj6" of the data of relative measurements only (Table 2) with the fixed calibration scale of the gravimeters of Hanover University and that of the combined adjustment "adj1" of both absolute and relative data.

Both absolute and relative measurements of the ties of the gravity micro-network agree very well (see results of "adj1", "adj5" and "adj6" in Tables 7 and 8).

The mean value and its standard deviation of the almost continuous measurements from 1 July to 3 August 2001 at point B3.090 using gravimeter FG5-108 are $(980925890.5 \pm 0.6) \mu G a l$. This confirms the good stability of the gravity field at the BIPM during ICAG-2001. 
Table 6b. Results of the measurements (expressed in microgals after subtraction of the reference value $980920000 \mu \mathrm{Gal})$ transferred to sites $\mathrm{A}$ and $\mathrm{B}$ at $0.9 \mathrm{~m}$.

\begin{tabular}{|c|c|c|c|}
\hline \multicolumn{4}{|c|}{ Transfer to A } \\
\hline \multicolumn{2}{|c|}{ Unweighted mean } & \multicolumn{2}{|c|}{ Weighted mean } \\
\hline$\overline{\hat{\widetilde{g}}_{\mathrm{A}}}$ & $5700.2 \pm 7.4$ & $\hat{\tilde{g}}_{\mathrm{A}, w}$ & $5701.2 \pm 5.5$ \\
\hline$\hat{\tilde{g}}_{\mathrm{A}}^{\mathrm{A}}$ & $5701.9 \pm 4.8$ & $\hat{\tilde{g}}_{\mathrm{A}, w}^{\mathrm{A}}$ & $5701.9 \pm 4.6$ \\
\hline$\hat{\tilde{g}}_{\mathrm{A}}^{\mathrm{A} 2}$ & $5701.2 \pm 6.9$ & $\hat{\tilde{g}}_{\mathrm{A}, w}^{\mathrm{A} 2}$ & $5700.6 \pm 7.2$ \\
\hline$\hat{\tilde{g}}_{\mathrm{A}}^{\mathrm{B}}$ & $5700.5 \pm 9.0$ & $\hat{\vec{g}}_{\mathrm{A}, w}^{\mathrm{B}}$ & $5702.1 \pm 5.7$ \\
\hline$\hat{\widetilde{g}}_{\mathrm{A}}^{\mathrm{B} 1}$ & $5696.7 \pm 8.2$ & $\hat{\vec{g}}_{\mathrm{A}, w}^{\mathrm{B} 1}$ & $5699.4 \pm 4.5$ \\
\hline \multicolumn{4}{|c|}{ Transfer to B } \\
\hline \multicolumn{2}{|c|}{ Unweighted mean } & \multicolumn{2}{|c|}{ Weighted mean } \\
\hline$\hat{\widetilde{g}}_{\mathrm{B}}$ & $8017.8 \pm 7.4$ & $\hat{\widetilde{g}}_{\mathrm{B}, w}$ & $8018.8 \pm 5.5$ \\
\hline$\hat{\widetilde{g}}_{\mathrm{B}}^{\mathrm{A}}$ & $8019.5 \pm 4.8$ & $\hat{\tilde{g}}_{\mathrm{B}, w}^{\mathrm{A}}$ & $8019.5 \pm 4.6$ \\
\hline$\hat{\widetilde{g}}_{\mathrm{B}}^{\mathrm{A} 2}$ & $8018.8 \pm 6.9$ & $\hat{\widetilde{g}}_{\mathrm{B}, w}^{\mathrm{A} 2}$ & $8018.2 \pm 7.2$ \\
\hline$\hat{\widetilde{g}}_{\mathrm{B}}^{\mathrm{B}}$ & $8018.0 \pm 9.0$ & $\hat{\vec{g}}_{\mathrm{B}, w}^{\mathrm{B}}$ & $8019.7 \pm 5.7$ \\
\hline$\hat{\widetilde{g}}_{\mathrm{B}}^{\mathrm{B} 1}$ & $8014.3 \pm 8.2$ & $\hat{\vec{g}}_{\mathrm{B}, w}^{\mathrm{B} 1}$ & $8017.0 \pm 4.5$ \\
\hline
\end{tabular}

Table 6c. Unweighted and weighted means of the results of the measurement at each site at $0.9 \mathrm{~m}$ (expressed in microgals after subtraction of the reference value $980920000 \mu \mathrm{Gal})$.

\begin{tabular}{llll}
\hline \multicolumn{2}{l}{ Unweighted mean } & \multicolumn{2}{l}{ Weighted mean } \\
\hline$\hat{\tilde{g}}_{\mathrm{A}}^{\mathrm{A}}$ & $5701.9 \pm 4.8$ & $\hat{\tilde{g}}_{\mathrm{A}, w}^{\mathrm{A}}$ & $5701.9 \pm 4.6$ \\
$\hat{\tilde{g}}_{\mathrm{A} 2}^{\mathrm{A} 2}$ & $5706.6 \pm 6.9$ & $\hat{\tilde{g}}_{\mathrm{A} 2, w}$ & $5706.0 \pm 7.2$ \\
$\hat{\vec{g}}_{\mathrm{B}}^{\mathrm{B}}$ & $8018.1 \pm 9.0$ & $\hat{\tilde{g}}_{\mathrm{B}, w}$ & $8019.7 \pm 5.7$ \\
$\hat{\tilde{g}}_{\mathrm{B} 1}^{\mathrm{B} 1}$ & $8010.0 \pm 8.2$ & $\hat{\tilde{g}}_{\mathrm{B} 1, w}$ & $8012.7 \pm 4.5$ \\
\hline
\end{tabular}

\subsubsection{Comparison between ICAG-2001 and ICAG-97}

Figure 5 shows the results of the combined adjustment of the relative and all absolute measurements during
Table 8. Comparison of results of the adjustment of data of relative measurements ("adj6") at each point and corresponding results of the combined adjustment of absolute and relative data ("adj1", see Tables 6 and 7). The results are expressed in microgals after subtraction of the reference value $980920000 \mu \mathrm{Gal} . \Delta_{1,6}$ is the difference between the results of "adj1" and "adj6" at point P.

\begin{tabular}{llllllr}
\hline No. & Point & adj6 & $m$ & adj1 & $M$ & $\Delta_{1,6}$ \\
\hline 1 & A.005 & 5968.2 & 0.7 & 5968.0 & 1.1 & -0.2 \\
2 & A.030 & 5887.6 & 0.4 & 5887.4 & 1.0 & -0.2 \\
3 & A.090 & 5701.2 & 0.0 & 5701.2 & 0.9 & 0.0 \\
4 & A.130 & 5580.4 & 0.4 & 5580.4 & 1.0 & 0.0 \\
5 & A2.005 & 5972.0 & 0.8 & 5971.8 & 1.1 & -0.2 \\
6 & A2.030 & 5890.5 & 0.5 & 5890.7 & 1.0 & 0.2 \\
7 & A2.090 & 5706.3 & 0.4 & 5706.6 & 0.9 & 0.3 \\
8 & A2.130 & 5586.8 & 0.5 & 5587.2 & 1.0 & 0.4 \\
9 & B.005 & 8273.4 & 1.0 & 8272.8 & 1.1 & -0.6 \\
10 & B.030 & 8197.6 & 0.8 & 8197.1 & 1.0 & -0.5 \\
11 & B.090 & 8019.3 & 0.7 & 8018.8 & 0.9 & -0.5 \\
12 & B.130 & 7900.2 & 0.7 & 7899.8 & 1.0 & -0.4 \\
13 & B1.005 & 8266.2 & 1.0 & 8265.1 & 1.1 & -1.1 \\
14 & B1.030 & 8191.0 & 0.9 & 8189.9 & 1.0 & -1.1 \\
15 & B1.090 & 8015.6 & 0.7 & 8014.5 & 0.9 & -1.1 \\
16 & B1.130 & 7901.4 & 0.8 & 7900.4 & 1.0 & -1.0 \\
17 & B3.005 & 8259.7 & 1.2 & 8259.0 & 1.3 & -0.7 \\
18 & B3.030 & 8183.3 & 0.9 & 8182.5 & 1.1 & -0.8 \\
19 & B3.090 & 8002.3 & 0.8 & 8001.7 & 1.0 & -0.6 \\
20 & B3.130 & 7886.4 & 0.9 & 7885.8 & 1.1 & -0.6 \\
21 & L3.005 & 6852.8 & 1.0 & 6852.1 & 1.2 & -0.7 \\
22 & L3.030 & 6783.4 & 0.7 & 6782.7 & 1.0 & -0.7 \\
23 & L3.090 & 6618.7 & 0.5 & 6618.1 & 0.9 & -0.6 \\
24 & L3.130 & 6510.8 & 0.6 & 6510.2 & 1.0 & -0.6 \\
25 & L4.005 & 6868.2 & 1.1 & 6868.0 & 1.3 & -0.2 \\
26 & L4.030 & 6798.7 & 0.7 & 6798.6 & 1.0 & -0.1 \\
27 & L4.090 & 6632.8 & 0.5 & 6632.8 & 0.9 & 0.0 \\
28 & L4.130 & 6522.1 & 0.7 & 6522.1 & 1.0 & 0.0 \\
\hline Standard deviation $0 f \Delta=$ & 0.5. & & & \\
\hline & & & & & &
\end{tabular}

ICAG-2001 (column 14 of Table 5a) and the results of the absolute measurements during ICAG-97 (Tables 5a and 7 and Figure 1 in [9]). All these results are transferred to point A.090. The unweighted mean value $\hat{\tilde{g}}_{\mathrm{A}}$ of all absolute measurements during ICAG-2001 (column 14 of Table 5a) is $(980925698.5 \pm 11.5) \mu \mathrm{Gal}$

Table 7. Comparison of the results of different versions of the adjustment of relative and absolute data of ICAG-2001.

Weighted mean of all the $g$ values transferred to points A, A2, B or B1 at height $0.9 \mathrm{~m}$ are expressed in microgals after subtraction of the reference value $980920000 \mu \mathrm{Gal}$. Differences $\Delta_{1, i}^{\mathrm{P}}$ are expressed in microgals. $M$ is the mean square error.

\begin{tabular}{|c|c|c|c|c|c|c|c|c|c|}
\hline \multirow{2}{*}{\multicolumn{2}{|c|}{ Adjustment }} & \multicolumn{2}{|c|}{ A.090 } & \multicolumn{2}{|c|}{ A2.090 } & \multicolumn{2}{|c|}{ B.090 } & \multicolumn{2}{|c|}{ B 1.090} \\
\hline & & $g-g_{\mathrm{r}}$ & $M$ & $g-g_{\mathrm{r}}$ & $M$ & $g-g_{\mathrm{r}}$ & $M$ & $g-g_{\mathrm{r}}$ & $M$ \\
\hline 1 & $\operatorname{adj} 1$ & 5701.2 & 0.9 & 5706.6 & 0.9 & 8018.8 & 0.9 & 8014.5 & 0.9 \\
\hline 2 & $\operatorname{adj} 2$ & 5700.5 & 0.8 & 5706.2 & 0.9 & 8018.3 & 0.8 & 8013.8 & 0.9 \\
\hline 3 & $\operatorname{adj} 3$ & 5698.5 & 2.2 & 5701.8 & 2.4 & 8018.2 & 2.2 & 8012.0 & 2.4 \\
\hline 4 & adj4 & 5700.9 & 1.2 & 5705.8 & 1.2 & 8019.1 & 1.2 & 8012.7 & 1.2 \\
\hline 5 & adj5 & 5701.4 & 1.2 & 5706.3 & 1.3 & 8019.6 & 1.3 & 8013.4 & 1.3 \\
\hline \multicolumn{2}{|c|}{ Difference } & \multicolumn{2}{|l|}{$\Delta_{1, i}^{\mathrm{A}}$} & \multicolumn{2}{|l|}{$\Delta_{1, i}^{\mathrm{A} 2}$} & \multicolumn{2}{|l|}{$\Delta_{1, i}^{\mathrm{B}}$} & \multicolumn{2}{|l|}{$\Delta_{1, i}^{\mathrm{B} 1}$} \\
\hline 7 & $i=2$ & \multicolumn{2}{|l|}{0.7} & \multicolumn{2}{|l|}{0.4} & \multicolumn{2}{|l|}{0.5} & \multicolumn{2}{|l|}{0.7} \\
\hline 8 & $i=3$ & \multicolumn{2}{|l|}{2.7} & \multicolumn{2}{|l|}{4.8} & \multicolumn{2}{|l|}{0.6} & \multicolumn{2}{|l|}{2.5} \\
\hline 9 & $i=4$ & \multicolumn{2}{|l|}{0.3} & \multicolumn{2}{|l|}{0.8} & \multicolumn{2}{|l|}{-0.3} & \multicolumn{2}{|l|}{1.8} \\
\hline 10 & $i=5$ & \multicolumn{2}{|l|}{-0.2} & \multicolumn{2}{|l|}{0.3} & \multicolumn{2}{|l|}{-0.8} & \multicolumn{2}{|l|}{1.1} \\
\hline 11 & $i=6$ & \multicolumn{2}{|l|}{0.0} & \multicolumn{2}{|l|}{0.3} & \multicolumn{2}{|l|}{-0.5} & \multicolumn{2}{|l|}{-1.1} \\
\hline
\end{tabular}




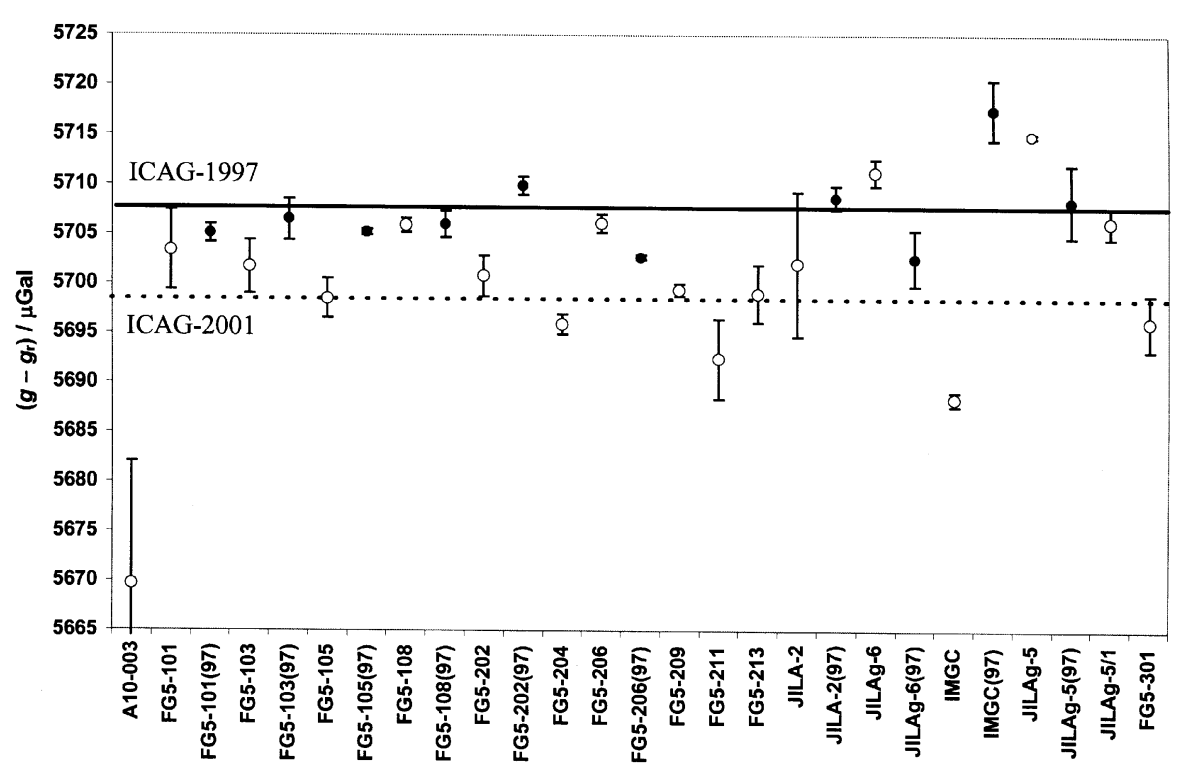

Figure 5. Results of absolute measurements at point A.090 during ICAG-2001 (०; Table 5) and ICAG-97 (•) for each gravimeter. Solid line: unweighted mean value of ICAG-97 (980 925 707.8 \pm 2.8$) \mu \mathrm{Gal}$; dashed line: unweighted mean value of all absolute measurements of ICAG-2001 (980925698.5 \pm 11.5$) \mu \mathrm{Gal}$.

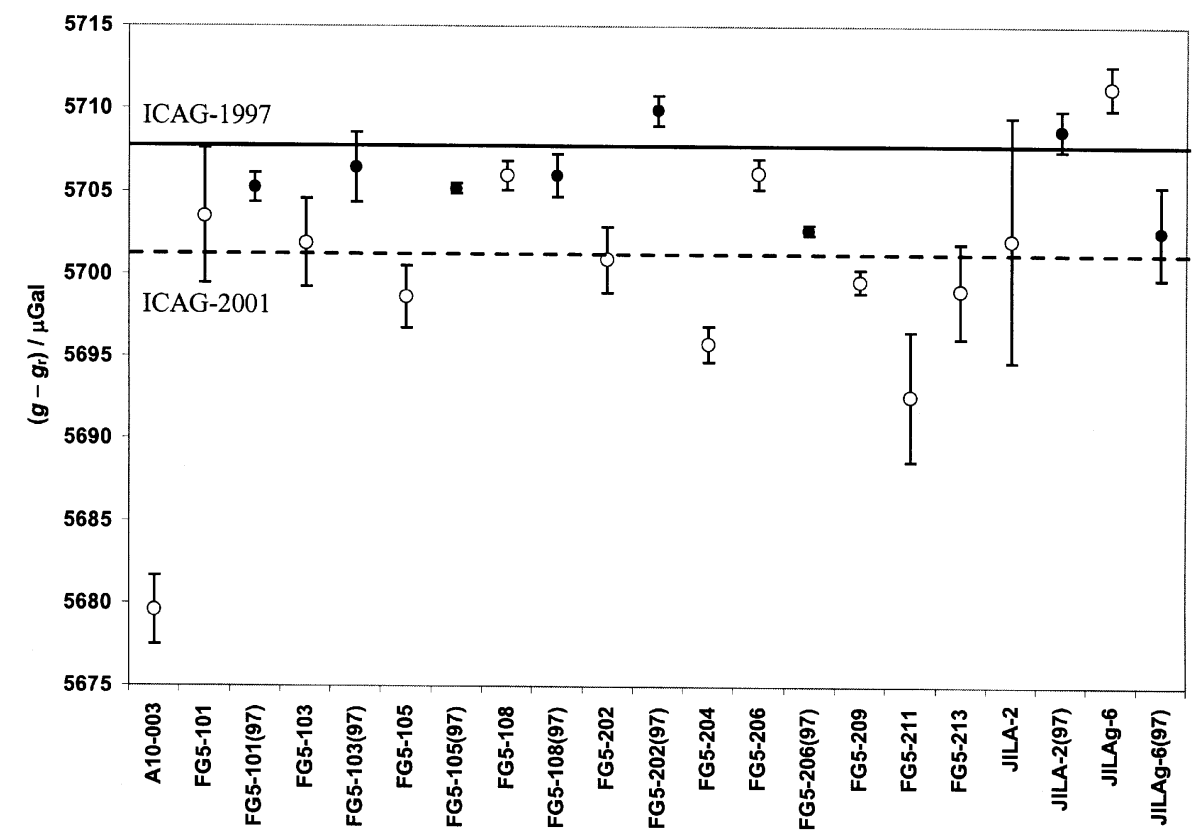

Figure 6. Results of absolute measurements at point A.090 during ICAG-2001 (०; Table 6) and ICAG-97 (•) for each gravimeter. Solid line: unweighted mean value of ICAG-97 (980925 707.8 \pm 2.8$) \mu \mathrm{Gal}$; dashed line: weighted mean value with some omitted data of absolute measurements of ICAG-2001 (980925701.2 \pm 5.5) $\mu \mathrm{Gal}$.

(Table 5b). In comparison, the unweighted mean value of all absolute measurements transferred to point A.090 during ICAG-97 was $(980925707.8 \pm 2.8) \mu \mathrm{Gal}$.

The results of the combined adjustment of the relative and absolute data of ICAG-2001 with some data omitted (column 14 of Table 6), are shown in Figure 6 together with the results of the absolute measurements during ICAG-97. The weighted mean $\hat{\widetilde{g}}_{\mathrm{A}, w}$ of the absolute measurements during ICAG-2001 is $(980925701.2 \pm 5.5) \mu \mathrm{Gal}$ (Table 6b).

The unweighted mean value of all the absolute measurements transferred to point A.090 during ICAG-2001 is $6.6 \mu \mathrm{Gal}$ lower than the weighted mean $\hat{\widetilde{g}}_{\mathrm{A}, w}$ obtained in ICAG-97. Note that the results of 
the measurements made using the BIPM absolute gravimeter FG5-108 at point A.090 in 1997 and 2001 coincide within $1 \mu \mathrm{Gal}$.

\section{Conclusions}

The $g$ values obtained as a result of a combined adjustment of the weighted data of the absolute and relative measurements during ICAG-2001 at sites A, $\mathrm{A} 2, \mathrm{~B}$ and $\mathrm{B} 1$ of the BIPM gravity micro-network are (Table 7):

$$
\begin{array}{ll}
\text { at A.090: } & 980925701.2 \mu \mathrm{Gal} \text {; } \\
\text { at A2.090: } & 980925706.6 \mu \mathrm{Gal} \text {; } \\
\text { at B.090: } & 980928018.8 \mu \mathrm{Gal} \text {; } \\
\text { at B1.090: } & 980928014.5 \mu \mathrm{Gal} .
\end{array}
$$

The standard uncertainty of these values is $5.5 \mu \mathrm{Gal}$ (6 parts in $10^{9}$ ), which is calculated as the weighted mean of the residuals (differences between the $g$ value obtained by each gravimeter at point A.090 and that obtained by the combined adjustment "adj1", see column 14 of Table 6a). This uncertainty is larger than that obtained at A.090 during ICAG-97 $(2.8 \mu \mathrm{Gal})$.

The $g$ value at A.090 obtained from thirteen absolute gravimeters during ICAG-2001 (Table 6a and Figure 6) is $6.6 \mu \mathrm{Gal}$ lower than the value obtained from fifteen gravimeters during ICAG-97. Eight of these gravimeters participated in both ICAG-97 and ICAG-2001. The results obtained in the two comparisons lie within $2 \mu \mathrm{Gal}$ (i.e. negligible difference) for two gravimeters; the difference $g_{2001}-g_{1997}$ is positive for two gravimeters and negative for the other four.

Comparison of the results of the combined adjustment of all the absolute gravimeter data (Table 5a and Figure 5) of ICAG-2001 with the results of ICAG-97 shows that the $g$ value at A.090 obtained by seventeen absolute gravimeters during ICAG-2001 is $9.3 \mu \mathrm{Gal}$ lower than the value obtained from fifteen gravimeters during ICAG-97. The differences $g_{2001}-g_{1997}$ are less than $2 \mu \mathrm{Gal}$ (i.e. negligible) for two gravimeters, positive for three gravimeters and negative for five gravimeters.

The maximum difference between the $g$ values at A.090 obtained during ICAG-2001 by the different gravimeters is $32 \mu \mathrm{Gal}$ (between JILAg-6 and A10003). If we omit the result of A10-003, which has a low weight (less than 0.1 , see Table 5a), the maximum difference is $19 \mu \mathrm{Gal}$ (between JILAg-6 and FG5-211).

The use during ICAG-2001 of both absolute and relative measurements of the BIPM gravity network, and the combined adjustment of the weighted absolute and relative data, have not reduced the uncertainty of the $g$ values obtained compared with the results of ICAG97. Taking into account the improvement in the BIPM sites, the increased number and improved measurements of the gravity gradients, and the demonstrated stability of the gravity field at site B during the principal part of the absolute measurements, one is forced to conclude that this situation is related to the performance and operation of the absolute gravimeters. It must be emphasized that the results of the measurements during ICAG-2001 and ICAG-97 using some of the absolute gravimeters are in good agreement. This testifies to the high potential performance of thoroughly maintained and properly operated gravimeters with well-investigated systematic uncertainties.

The technical protocol should be developed and adopted for future comparisons. It should regulate their organization, measurement strategy and methods of data processing, the calculation of uncertainties including the budget of systematic uncertainties for individual gravimeters following the recommendations usually used in metrology [11, 18], and presentation of the results.

It is important that such comparisons include various types of absolute gravimeter, developed using different basic principles (free fall of massive test bodies or atomic interferometry) and different designs (for example dropping mechanics, interferometer layout, interference fringe detectors and counters, data-acquisition electronics, type of laser radiation (for example at $633 \mathrm{~nm}$ or $532 \mathrm{~nm}$, modulated or unmodulated in frequency), vibro-isolation system for reference reflector, etc.).

Further investigation of the sources of systematic uncertainties is necessary to complete the calculation of the uncertainty budget and to improve understanding of the remaining discrepancies in the results of the absolute measurements.

Regular monitoring of the gravity field at the BIPM using the BIPM absolute gravimeter is important to ensure that possible changes between the results of ICAG comparisons do not arise from changes in $g$ values at the sites of the BIPM gravity micro-network.

In ICAG-2001, good agreement was obtained between the results of the adjustment of only relative data ("adj6") and combined adjustment of relative and absolute data ("adj1"). Nevertheless, the relative measurements of the ties of the BIPM gravity network and the gradients at the sites, to ensure their stability and investigate the discrepancies between the ties and gradients obtained in 1997 and 2001, are still important for comparisons of absolute gravimeters and require quite distinct organization.

Acknowledgements. The authors wish to thank Dr T. J. Quinn, the Director of the BIPM, and all staff members for their invaluable support.

\section{References}

1. Boulanger Yu. D., Arnautov G. P., Scheglov S. N., 1981, Bull. Inf. Bur. Grav. Int., 1983, 52, 99-124.

2. Becker M., Groten E., Bull. Inf. Bur. Grav. Int., 1983, 52, 86-96.

3. Boulanger Yu., Faller J., Groten E., Arnautov G., Becker M., Beetz H., Beruff R., Cannizzo L., Cerutti G., 
Feng-Youg Yuan, Guo Yuguang, Haller L. A., Hanada H., Hollander W., Huang Da-Lun, Kalish E., Marson I., Niebauer T., Poiteven C., Richter B., Röder R., Sakuma A., Sands R., Sasagawa G., Scheglov S., Schnüll M., Spita W., Stus Yu., Tarasiuk W., Wenzel G., Zhang Guang-Yuan, Zhou Juing-Hua, Zhou Kungen, Zumberge M., Bull. Inf. Bur. Grav. Int., 1986, 59, 89-103.

4. Becker M., Bull. Inf. Bur. Grav. Int., 1985, 57, 46-71.

5. Boulanger Yu. D., Faller J., Groten E., Arnautov G., Becker M., Bernard B., Cannizzo L., Cerutti G., Courtie N., Feng Youg-Yuan, Fried J., Guo You-Guang, Hanada H., Huang Da-Lun, Kalish E., Klopping F., Li De-Xi, Leord J., Makinen J., Marson I., Ooe M., Peter G., Röder R., Ruess D., Sakuma A., Schnüll N., Stus F., Scheglov S., Tarasyuk W., Timmen L., Torge W., Tsubokawa T., Tsuruta S., Vänskä A., Zhang Guang-Yuan, Bull. Inf. Bur. Grav. Int., 1991, 68, 24-44.

6. Becker M., Bernard B., Boulanger Yu., Corrado G., Faller J., Fried J., Groten E., Hanada H., Lindner K., Meurers B., Peter G., Röder R., Ruess D., Timmen L., Toto B., Tsuruta S., Zürn W., Bull. Inf. Bur. Grav. Int., 1990, 67, 152-159.

7. Marson I., Faller J. E., Cerutti G., De Maria P., Chartier J.-M., Robertsson L., Vitushkin L., Friedrich J., Krauterbluth K., Stizza D., Liard J., Gagnon C., Lothhammer A., Wilmes H., Makinen J., Murakami M., Rehren F., Schnüll M., Ruess D., Sasagawa G. S., Metrologia, 1995, 32, 137-144.

8. Becker M., Balestri L., Bartell R., Berrino G., Bonvalot S., Csapó G., Diament M., D’Errico M., Gerstenecker C., Gagnon C., Jousset P., Kopaev A., Liard J., Marson I., Meurers B., Novak I., Nakai S., Rehren F., Richter B., Schnüll M., Somerhausen A., Spita W., Szatmári G., Van Ruymbeke M., Wenzel H.-G., Wilmes H., Zucchi M., Zürn W., Metrologia, 1995, 32, 145-152.
9. Robertsson L., Francis O., van Dam T. M., Faller J., Ruess D., Delinte J.-M., Vitushkin L., Liard J., Gagnon C., Guo You Guang, Huang Da Lun, Fang Yong Yuan, Xu Jin Yi, Jeffries G., Hopewell H., Edge R., Robinson I., Kibble B., Makinen J., Hinderer J., Amalvict M., Luck B., Wilmes H., Rehren F., Schmidt K., Schnull M., Cerutti G., Germak A., Zabek Z., Pachuta A., Arnautov G., Kalish E., Stus Y., Stizza D., Friederich J., Chartier J.-M., Marson I., Metrologia, 2001, 38, 71-78.

10. Becker M., Berrino G., Camacho A. G., Falk R., Francis O., Gagnon C., Gerstenecker C., Liard J., Läufer G., Meurers B., Navarro F.-J., Nowak I., Rehren F., Riccardi U., Richter B., van Ruymbeke M., Schmidt K., Schnüll M., Stizza D., Friederich J. E., Vauterin P., Wilmes H., Bull. Inf. Bur. Grav. Int., 2001, 85, 61-72.

11. Mutual recognition of national measurement standards and of calibration and measurement certificates issued by national metrology institutes, International Committee for Weights and Measures, 1999, available from http://www.bipm.org.

12. Boedecker G., Bull. Inf. Bur. Grav. Int., 1998, 83, 25-27.

13. Niebauer T. M., Sasagawa G. S., Faller J. E., Hilt R., Klopping F., Metrologia, 1995, 32, 159-180.

14. Jiang Z., Zuo C., Qiu Q., Xu S., Scientia Sinica B, 1988, 38(9), 1143-1152.

15. Vitushkin L. et al., BIPM Rapport, in preparation, 2002.

16. Kanngiesser E., Kummer K., Torge W., Wenzel H.-G., Das Gravimetereichsystem Hannover, Wiss. Arb. d. Fachrichtung Verm. Wesen der Univ. Hannover, Nr 120, Hanover, 1983.

17. Becker M., Circular letter No. R6 to ICAG-2001 participants, 15 August 2001.

18. Guide to the Expression of Uncertainty in Measurement, Geneva, International Organization for Standardization, 1993. 